\title{
Extended Range Forecast of Monsoon at Smaller Spatial Domains over India for Application in Agriculture
}

\section{R. Pattanaik ( $\sim$ pattanaik_dr@yahoo.co.in )}

India Meteorological Department https://orcid.org/0000-0002-0251-4959

\section{Ashish Alone}

India Meteorological Department

\section{Praveen Kumar}

India Meteorological Department

R. Phani

Indian Institute of Tropical Meteorology

\section{Raju Mandal}

Indian Institute of Tropical Meteorology

\section{Avijit Dey}

Indian Institute of Tropical Meteorology

\section{Research Article}

Keywords: Extended range forecast, active-break cycle, CFSv2, Multi-model ensemble, Met-subdivision level forecast

Posted Date: July 15th, 2021

DOl: https://doi.org/10.21203/rs.3.rs-499061/v1

License: (c) (1) This work is licensed under a Creative Commons Attribution 4.0 International License. Read Full License

Version of Record: A version of this preprint was published at Theoretical and Applied Climatology on October 31st, 2021. See the published version at https://doi.org/10.1007/s00704-021-03827-2. 


\section{Abstract}

The performance of operational extended range forecast (ERF) issued by IMD is evaluated for the southwest monsoon 2020. The early onset of monsoon over the Bay of Bengal and the normal onset of monsoon over Kerala with slightly rapid progress northward are very well captured in the ERF with two to three weeks lead time. The ERF also captured very well the transitions from normal to weaker phase of monsoon in July, the active phase of monsoon in entire August was well anticipated in ERF with a lead time of 3 weeks. The active monsoon condition in the second half of September associated with delayed withdrawal from northwest India was also reasonably well captured in the ERF. Quantitatively, the ERF shows significant skill up to three weeks on all India levels. The spatial distribution of met-subdivision level mean forecast skill of predicting above normal, normal and below normal categories in terms of correct (forecast and observed category matching) and partially correct (forecast and observed category out by one category) for the 36 subdivisions during the entire monsoon season of 2020 is found to be $89 \%, 83 \%, 80 \%$ and $78 \%$ for week 1 to week 4 forecasts respectively. The wrong forecasts (forecast and observed category out by two categories) are found to be between $11 \%$ in week 1 to $22 \%$ in week 4 forecast. Thus, the met-subdivision level forecast shows useful skill and is being used operationally for agrometeorological advisory services of IMD.

\section{Introduction}

The forecasting of southwest monsoon rainfall on extended range time scale (prediction of active-break cycle of monsoon) is vital for issuing reliable advisories to the farming communities of the vast agroeconomic country like India, where the Agriculture production is directly influenced by monsoon performance (Gadgil and Gadgil, 2006). The extended range forecast (ERF) of monsoon in 3 to 4 weeks' time scale can enable tactical adjustments to the strategic decisions that are made based on the longerlead seasonal forecasts particularly for the farmers. Since 2009 India Meteorological Department (IMD) has been issuing the operational ERF based on multi-model ensemble (MME) from different modeling products viz., National Centre for Environmental Prediction's (NCEP's) Climate Forecast System (CFS), European Centre for Medium Range Weather Forecasting (ECMWF) and the JMA's ensemble prediction model (Pattanaik et al. 2013; Pattanaik 2014; Pattanaik et al. 2019). In the year 2017 IMD implemented CFS version 2 (CFSv2) coupled model for the operational ERF. As discussed in the recent paper by Pattanaik et al. (2020), the operational ERF during different intra-seasonal episodes of monsoon during 2017 and 2018 including the onset, withdrawal and transition from active to break and vice versa are mostly well captured. Just like every monsoon is different the monsoon of 2020 is also very unique in the sense that the departure of seasonal rainfall over India is found to close to $109 \%$ of its Long Period Average (LPA) of $88 \mathrm{~cm}$, which is subsequent to the excess monsoon year of 2019 having rainfall departure of $110 \%$ of its LPA. The end of monsoon season report by IMD (IMD, 2020) has shown that the monsoon season 2020 witnessed very heavy rainfall spells over many parts of India leading to flood conditions over several parts of India. The development of the La Niña is one of the factors which helped to get above normal rainfall activity during the second half of the season. 
IMD has been using operational medium and extended range forecast for application in Agriculture by giving agrometeorological advisories to farmers. A number of studies showed the usefulness of medium range weather forecast in Indian agriculture (Rathore et al. 2009; Chattopadhyay et al. 2016). The agrometeorological advisories are prepared by IMD based on the real-time weather forecast and it is proved to be useful in the decision-making process in every farm operation, crop planning, rain water harvesting, irrigation scheduling, control of pests \& diseases etc (Chattopadhyay et al. 2018). As shown in this study in case of intermittent flash flood during Kharif season of 2015 over Assam, different situations (flooding period) were created depending on land situation, soil types and nearness of the crop field to the source of the flood. The weather information (weather forecast) available at that time was very much useful in managing the situation arising due to the excess rainfall through real time agrometeorological advisories. Similar to the agrometeorological advisory in medium range, a real time monitoring of intra-seasonal fluctuation of monsoon rainfall in the extended range time scale can also benefit the farmers through a proper advisory. The operational ERF issued by IMD during 2009 monsoon season was also quite useful in assessing the extent and gravity of drought situation of the country (Tyagi and Pattanaik, 2010). Similarly, the dry spells during the recent monsoon seasons of 2017 and 2018 are also very well captured in the real time (Pattanaik et al. 2020), which was used operationally for issuing advisories to farmers. A recent study by Robertson et al. (2019) demonstrated the two weeks ERF issued in real-time during June-September 2018 monsoon period for the four districts of the one of the eastern states of India, viz., Bihar. These successful forecasts of onset and break phases during monsoon 2018 over Bihar are related to episodes of the Madden Julian Oscillation (MJO), which the model is shown to capture quite well at 1-2 week lead. Thus, the agrometeorological advisories based on operational ERF have tremendous economic value for the country like India. A study highlighting the socio-economic benefits of Agrometeorological Services in India was carried out by reputed National Council of Applied Economic Research (NCEAR), Delhi and found that the farming communities of the country is using agrometeorological advisory Service products for critical actions during their farm operations (Sharma, 2015). Considering the significant importance of ERF in providing services to Agriculture sector the present paper discusses the performance of ERF up to 3 to 4 weeks during the monsoon season 2020 at smaller spatial scales covering 36 meteorological sub-divisions of India.

\section{Model Used And Methodology Of The Study}

The current operational ERF modeling system of IMD is based on the CFSv2 coupled model adopted from NCEP (Saha et al. 2014). The CFSv2 has the capability of simulating MJO in a better way compared to that of CFsv1 (Saha et. al. 2014; Pattanaik and Kumar 2014). The present ERF system of IMD was initially adopted at IITM Pune, which has the capability of predicting active-break cycle of monsoon which can be used for various applications (Sahai et al. 2013, 2015). The atmospheric version of the model is the Global Forecast System (GFS) model and the oceanic component is the GFDL Modular Ocean Model V.4 (MOM4). The suite of models consists of (i) CFSv2 at T382 (ii) CFSv2 at T126 (iii) GFSbc (bias corrected SST from CFSv2) at T382 and (iv) GFSbc at T126 with 4 members each (Total 16 members). The present ERF system of IMD is running operationally once in a week based on Initial 
Condition (IC) of every Wednesday and the forecast is generated for 4 weeks starting from subsequent Friday to Thursday and so on. The hindcast run for 17 years (2003 to 2019) along with the operational run during different phases of monsoon 2020 carried out based on the ICs of every Wednesday (Fig. 1). The atmosphere and ocean ICs are available from the Global Data Assimilation System (GDAS) and Global Ocean Data Assimilation System (GODAS) run at NCMRWF and INCOIS respectively (Fig. 1). The daily precipitation analysis over Indian region obtained from merged rain-gauge data with the TRMM TMPA satellite-derived rainfall estimates are used for the verification of the model forecasts (Mitra et al., 2009).

\section{Observed Intra-seasonal Activity Of Southwest Monsoon 2020}

During 2020 the onset and progress phase of monsoon was associated with interaction with the two cyclonic storms (CSs) viz., the super cyclone 'AMPHAN' over the Bay of Bengal during 15-21 May and the CS 'NISARGA' over the Arabian Sea during 01-04 June (RSMC 2020). The southwest monsoon arrived over the Bay of Bengal on 17th May 2020, 5 days ahead of its normal date associated with the Super CS, "AMPHAN". However, the further progress was delayed and the onset over Kerala (Southern tip of India) was on the normal date of 1 st June. The progress of monsoon was slightly faster and it covered the entire country on 26th June, 12 days before its normal date of 08th July. The CS 'NISARGA' over the Arabian Sea helped in bringing the monsoon to Kerala (Southern tip of India) and also in giving above normal rainfall during initial period of the season, which can be seen from the daily observed rainfall over the country as a whole along with its normal (Fig. 2).

As indicated in the end of the monsoon season report (IMD, 2020) and also reflected in Fig. 2, the monsoon rainfall was above normal during June for many days with faster progress of monsoon to the north after its onset. However, during the month of July, many unfavourable features of monsoon appeared resulting in deficient rainfall for the country. The weak monsoon in July as shown in Fig. 2 was mainly due to absence of any major monsoon disturbance over Bay of Bengal and due to the prevalence of a weak cross equatorial flow in general. Absence of any major systems caused the monsoon trough also to remain in weak condition and was to the north of the normal position or close to the foothills of the Himalayas on many days during the month. It resulted in frequent and prolonged floods over northeastern India and Indo-Gangetic plains close to foothills of the Himalayas. At the same time, major parts of central and northwest India received deficient rainfall (IMD, 2020). During the month of August, strengthening of the monsoon flow in the Arabian Sea, led to convergence of strong low-level westerlies along the west coast with most of the days it was associated with above normal rainfall (Fig. 2). The formation of many low pressure systems in the month of September led to an active monsoon trough which delayed the withdrawal of monsoon from northwest India and it commenced on 28th September from some parts of Northwest India, against its normal date of 17th September.

Thus, the main highlights of intra-seasonal variability of monsoon 2020 are : early onset over Andaman Sea and normal onset over Kerala, relatively faster progress of monsoon to the north India, slightly below 
normal rainfall during July, very active August rainfall and active monsoon in September and delayed withdrawal of monsoon.

\section{Verification Of Erf During Different Phases Of Monsoon 2020}

As discussed above, the following intra-seasonal episodes are considered for the verification of ERF forecast during 2020 monsoon season.

\subsection{Early onset over the Bay of Bengal and the normal onset over Kerala}

During 2020 the onset and initial progress phase of monsoon was influenced by two cyclones viz., the 'AMPHAN' super cyclone over the Bay of Bengal during 15-21 May and the cyclonic storm 'NISARGA' over the Arabian Sea during 01-04 June, 2020 (RSMC, 2020). Although the onset over the Bay of Bengal was ahead of normal, the onset over Kerala was on the normal date of 1st June. The cyclonic storm "AMPHAN" over the Bay of Bengal during the period from 15-21 May had resulted into the onset over the Bay of Bengal, which can be seen from the positive observed rainfall anomalies over the Bay of Bengal in the top panel of Fig. 3a. The same can be seen as well in the ERF for the target week of 15-21 May with two weeks lead time based on ICs of 13th May and 06th May (Bottom panel of Fig. 3a). However, the week 3 forecast based on the IC of 29th April for the same target week could not capture the convective activity over the Bay of Bengal as indicated with negative rainfall anomalies. Similarly, the normal onset of monsoon over Kerala (Southern tip of Indian mainland) is also well reflected from the observed rainfall anomalies during the week from 29 May to 04 June, 2020, which indicated positive anomalies of rainfall associated with the cyclonic storm 'NISARGA' over the Arabian Sea and western coast of India (Top panel plot in Fig. 3b). The same is very well predicted with two weeks lead time based on the initial conditions of 27 May and 20 May (Bottom panel plot of Fig. 3b) with an indication of normal onset over Kerala. In this case also the week 3 forecast based on the IC of 13 May could not capture the positive anomalies of rainfall associated with cyclone "NISARGA". With regard to the onset of monsoon over Kerala the daily time series of forecast rainfall over Kerala coast averaged over the region 75-77.5E, 05-7.5N clearly indicated increase of rainfall from 29th May onwards compared to its hindcast mean values shown in Fig. 4. Thus, the forecast based on 20th May clearly indicated likely onset of monsoon during the week from 29th May-04 June and it may be mentioned here that IMD declared the onset of monsoon over Kerala on 1st June (IMD, 2020).

\subsection{Relatively faster progress of monsoon to the north India.}

As seen from the Fig. $4 \mathrm{~b}$ above, the onset and active monsoon condition during the week was reasonably well captured for the period from 29 May-04 June 2020. As seen from Fig. 2 the rainfall is increased after the onset during the first week of June, however it decreases for few days after that and again increased from 11th of June taking the monsoon to northern part of the country. During the month of June, apart from the 'NISARGA' cyclone, a low pressure area which was formed over West central Bay of Bengal (9- 
12 June) and its associated cyclonic circulation have strengthened the monsoon flow. To see the progress phase of monsoon the ERF of rainfall is prepared for the target weeks of 05-11 June and 1218 June, 2020 with forecast lead time of three weeks (Fig. 5a-b). During the period of 05-11 June the rainfall activity was decreased as indicated by negative anomaly over most of India (upper panel plot in Fig. 5a) is reasonably well captured in the ERF at least for week 1 and week 2 forecasts, however, the week 3 forecast based on the IC of 20th May captured the positive anomalies over southern peninsula but the pocket of positive anomalies over the western coastal region of India could not capture well (Lower panel plots in Fig. 5a). The active phase of monsoon over peninsula and central India during the period from 12-18 June 2020 as represented by positive rainfall anomalies (upper panel plot in Fig. 5b) was well captured in the ERF with week 1 to week 3 leads with ICs of 11 June, 03 June and 27 May respectively (Lower panel plots in Fig. 5b).

\subsection{Slightly below normal rainfall during July}

During the month of July, many unfavourable features of monsoon appeared resulting in deficient rainfall for the country during the period as shown in Fig. 2 the daily rainfall averaged over India indicates normal to weak spells of monsoon rainfall in many days of the month of July. The weak monsoon in July was mainly due to absence of any major monsoon disturbance over the Bay of Bengal and due to the prevalence of a weak cross equatorial flow in general. Absence of any major systems caused the monsoon trough also remained weak with the monsoon trough lay to the north of the normal position or close to the foothills of the Himalayas on many days during the month (IMD, 2020). It resulted in frequent and prolonged floods over north-eastern India, met-subdivisions close to the foothills of the Himalayas. At the same time, major parts of central and northwest India received deficient rainfall like typical break conditions (Rajeevan et al. 2010; Krishnan et al. 2000). The Madden Julian Oscillation (MJO) is one of the oscillations in the tropics with a period typically ranging from 30-60 days (Madden and Julian 1971), can influence the intra-seasonal variability of monsoon. During the northern summer monsoon season there is a northward propagating component of MJO, which is commonly known as Monsoon IntraSeasonal Oscillation (MISO) describing the northward propagation of convective band over India (Yasunari, 1979; Sikka and Gadgil 1980; Pattanaik 2003). The RMM1 and RMM2 indices proposed by Wheeler and Hendon (2004) is used widely for MJO forecasts. Similarly, the MISO indices proposed by Suhas et al. (2013) have defined two indices MISO1 and MISO2, which are the principal components of extended empirical orthogonal functions (EEOFs) based on a covariance matrix created from $60^{\circ} \mathrm{E}$ to $95^{\circ} \mathrm{E}$ averaged rainfall data, which show latitudinal variation in the data and the favourable region of convection. Thus, the capability of numerical models in capturing MISO/MJO signals is very crucial in capturing the active/break cycle of monsoon.

The forecast Monsoon Intra-Seasonal Oscillation (MISO) as shown in Fig. 6d based on 08th July IC indicates very weak MISO with practically no northward propagation during the period. In order to see the performance of ERF forecast for this phase of monsoon the three weeks forecast rainfall anomaly along with the observed rainfall anomaly for the target weeks of 10-16 July, 17-23 July and 24-30 July, 2020 are shown in Figs. 6a-c respectively. As seen from the Fig. 6a the weak phase of monsoon rainfall over 
northwest and central India and above normal rainfall over south peninsula and foothills of India was well captured in the ERF with 2 to 3 weeks lead time. During the subsequent two weeks monsoon conditions were slightly weak over central and northwest parts of India, however, it was above normal over foothills region and some parts of the south peninsula, which was also well captured in the ERF with lead time of 2 to 3 weeks (Fig. 6b-c).

\subsection{Very active August rainfall.}

The Madden Julian Oscillation of (MJO) conditions showed that it was not very coherent during June and on most days of July. Only towards the end of July up to middle of August, the signal became active and slight eastward propagation from Indian Ocean to the maritime continent was seen. The same was also seen in the ERF forecast based on 5th August for a period of 4 weeks as shown in Fig. 7a. As the MJO moved eastwards over the Indian Seas, the Arabian Sea and Bay of Bengal became convectively active in August. The MISO forecast based on 05th August also indicated northward propagation from south peninsula and adjoining central India to central India and northern India (Fig. 7b).

The formation of five low pressure systems over the North Bay of Bengal in succession out of which four of them became well marked (4-10,9-11, 13-18,19-26 and 24-31 August) and their west-northwestward movement across central India up to Gujarat and south Rajasthan, active MJO and active monsoon trough mostly south of its normal position during many days in the month led to active monsoon conditions over most parts of the country and caused significantly higher than normal rainfall over central and western parts of India during the month of August (IMD, 2020). The active phase of rainfall for three weeks period from 07-13 August, 14-20 August and 21-27 August, 2020 can be seen in Fig. 8a-c with most parts of central and north-western parts of India having positive anomaly of observed rainfall in the top panel figures. The corresponding forecast rainfall anomaly also clearly captured the active phase of monsoon with three weeks lead time for the three consecutives active weeks from 07-13, 14-20 and 21-27 August, 2020 as shown in bottom panel plots in Fig. 8a-c).

\subsection{Active monsoon in September and delayed withdrawal of monsoon.}

The formation of two low pressure areas (on 13th Sep \& 20th Sep) in the month of September led to an active monsoon trough which delayed the withdrawal of monsoon from northwest India. The withdrawal of monsoon commenced on 28th September from some parts of northwest Rajasthan, against its normal date of 17th September (IMD, 2020). One low pressure area formed off north Andhra coast (eastern coastal state of India) on 13 September, which dissipated on 16th, however, the monsoon trough which was shifted to the north associated with the dissipation of the system, regained it near-normal position with the formation of another low pressure system on 20th over Northeast Bay of Bengal and neighbourhood. This low pressure system dissipated over east Bihar and neighbourhood on 26th. Apart from the above two low pressure systems in the month, another low-pressure system (6-8 September) formed over Southeast and adjoining East central Arabian Sea and in conjunction with an east-west 
shear zone over south peninsula caused widespread rainfall activity over south Peninsular India, Lakshadweep area and coastal and interior parts of Maharashtra during the first week of the month (IMD, 2020). Circulation features favouring convergence of strong moist winds from the Bay of Bengal in the lower tropospheric levels and the alignment of monsoon trough over northeast India and adjoining east India continued to trigger the monsoon activity over the region during the month. The ERF forecast 850 hPa wind for 4 weeks based on IC of 9th September (Fig. 9a) clearly indicated presence of east-west shear line along the latitude belt of about $18^{0} \mathrm{~N}$ and non-establishment of anticyclone over the northwest India at least up to two weeks (during 11-17 Sep \& 18-24 Sep) indicated a likely delay of monsoon withdrawal. The weekly observed rainfall anomaly for the period from 11-17 Sep 2020 shown in top panel plot of Fig. $9 \mathrm{~b}$ indicated positive anomaly over southern and western parts of India as shown in the top panel plot. Similarly the top panel plot in Fig. $9 \mathrm{c}$ also indicated positive anomaly of observed rainfall during 18-24 September, 2020 over parts of central and northwest India leading to delayed withdrawal of monsoon. The corresponding ERF rainfall anomalies for the target weeks of 11-17 and 18-24 September, 2020 also indicated the similar patterns of rainfall anomalies 2/3 weeks in advance with likely delay of withdrawal of monsoon from northwest India.

\section{Met Sub-division Forecast For Agricultural Applications During 2020 Monsoon}

\subsection{Met-subdivision mean forecast for the monsoon season 2020.}

Before the met-subdivision forecast skills are analysed it is useful to see the ERF skill over India as a whole. In order to see the quantitative verification of real-time ERF over the country as a whole, the observed weekly rainfall departure for country as a whole during the period of 2020 monsoon season is correlated with the corresponding ERF rainfall up to four weeks lead time. The observed weekly rainfall departures along with the corresponding ERF rainfall departure for the country as a whole with different lead time is shown in Fig. 10 along with the correlation coefficients (CC). As seen from Fig. 10 the ERF did capture the observed intra-seasonal variability of monsoon rainfall during different phases of monsoon such as onset, active \& break phases and also the withdrawal phase in most of the period during the season with significant CC between observed and forecast rainfall departure is found and is skilful up to 3 weeks.

Though the ERF of monsoon on all India level is very useful, due to the spatial inhomogeneity of the rainfall distribution for agricultural application two factors are necessary to be considered viz., (i) forecast over 36 met-subdivisions of India as shown in Fig. 11a and secondly (ii) the skill in terms of rainfall category will be more useful compared to the actual rainfall departure. Thus, due to increased variability, the forecast skill over smaller spatial domain in terms of actual rainfall departure is not expected to provide meaningful results particularly for the Agricultural applications. Thus, for verification at meteorological subdivisions level in place of actual rainfall departure, the category of the met-subdivision 
based on the observed rainfall departure is compared with the ERF category of the met-subdivision for different lead times. The forecast about the active-break cycles of monsoon two to three weeks in advance is of great importance for agricultural planning (sowing, harvesting, etc.), which can enable tactical adjustments to the strategic decisions that are made based on the longer-lead seasonal forecasts, and also will help in timely review of the ongoing monsoon conditions for providing outlooks to farmers. As discussed by Pattanaik (2014) the met-subdivision wise category forecasts for monsoon 2012 was very skilful for application in issuing agrometeorological advisories. Similarly, a recent study by Robertson et al., (2019) also demonstrated the two weeks ERF issued in real time during JuneSeptember 2018 monsoon period for the four districts of the state of Bihar in India (Sub division no 9 in Fig. 11a) could predict the monsoon onset and break phase forecasts related to episodes of the MaddenJulian Oscillation quite well at 1-2 week lead.

In order to see the skill of ERF for smaller spatial domains the 36 met-subdivisions (Fig. 11a) of India the observed weekly rainfall departure over each met- subdivisions the met subdivision is categorised in to five categories like (i) Large Excess (LE), Excess (E), Normal (N), Deficient (D) and Large Deficient (LD) or no rain as per the rainfall departure given in Table 1a. For agricultural applications some of the categories are merged and formed into 3 broad categories with 'LE' and 'E' categories combined into above normal' and 'D' \& 'LD' into below normal as shown in Table 1a. For the verification purpose over met-subdivision level the 3 categories [(Above Normal, AN); (Normal, NN); (Below Normal, BN)] are considered for preparing the contingency Table $1 \mathrm{~b}$. As seen in Table $1 \mathrm{~b}$ the forecast met subdivision is considered to be correct (C) if the forecast category matches with the observed category, partially correct (PC) if it is one category out and wrong if it is two or more categories out. Based on this contingency Table $1 \mathrm{~b}$ the verification skill score of met-subdivision level forecast in terms of correct (C), partially correct (PC) and wrong (W) forecast for the entire monsoon season 2020 is shown in Fig. 11b. Similarly, the spatial distribution of met-subdivision level mean forecast skill in terms of correct (C), partially correct (PC) and wrong $(W)$ forecast for the 36 subdivisions during the entire monsoon season of 2020 is shown in Figs. $12 \mathrm{a}-\mathrm{I}$.

Table 1a-b: (a) Classification of met-subdivision as normal, above normal and below normal based on rainfall departure in a week (b) Contingency table considered for verification of sub-division level forecast.

(a) 


\begin{tabular}{|lll|}
\hline Categories & Subdivision Rainfall Departure in a week & Classification \\
\hline Excess (E) & $+20 \%$ or more & Above Normal (AN) \\
Large Excess (LE) & $+60 \%$ or more & \\
\hline Normal (NN) & $-19 \%$ to $+19 \%$ & Normal (NN) \\
\hline Deficient (D) & $-20 \%$ or less & Below Normal (BN) \\
Large Deficient (LD) & $-60 \%$ or less & \\
No Rain (NR) & $-100 \%$ & \\
\hline
\end{tabular}

(b)

\begin{tabular}{|llll|}
\hline $\begin{array}{l}\text { Forecast Categories } \\
\text { Observed Categories }\end{array}$ & Above Normal (AN) & Normal (NN) & Below Normal (BN) \\
\hline Above Normal (AN) & Correct (C) & Partially Correct (PC) & Wrong (W) \\
\hline Normal (NN) & Partially Correct (PC) & Correct (C) & Partially Correct (PC) \\
\hline Below Normal (BN) & Wrong (W) & Partially Correct (PC) & Correct (C) \\
\hline
\end{tabular}

As seen in Fig. 11b, the correct percentage gradually decreases and is $58 \%$ for week 1 forecast, $45 \%$ for week 2 forecast, $38 \%$ for week 3 forecast and $34 \%$ for week 4 forecasts. It may be mentioned here that in case of normal ERF (when all the metsubdivisions are considered to be of normal (NN) category in the ERF for the entire season), the mean percentage of correct forecast during the 18-week period for 2020 is found to be about $22 \%$. Thus, in terms of statistical score the ERF at met-subdivision level forecast is better than the climatology forecast till 4 weeks. It is also seen in Fig. $11 \mathrm{~b}$ that the partially correct category forecast is $31 \%$ of the met-subdivisions in week $1,38 \%$ in week $2,42 \%$ in week 3 and $44 \%$ in case of week 4 forecast. With regard to the wrong forecast, it is $11 \%$ in week 1 forecast to $22 \%$ in week 4 forecast. Thus, it is very clear from Fig. $11 \mathrm{~b}$ that the mean percentage of correct to partially correct (one category out) forecast for the total number of met-subdivisions is found to be $89 \%$ in week 1 forecast, $83 \%$ in week 2 forecast, $80 \%$ in week 3 forecast and $78 \%$ in week 4 forecast, which is found to be very skilful for issuing the agrometeorological advisories to farmers.

The corresponding percentage of forecast categories (C, PC and W) at met-subdivision level in the decreasing order of correct categories percentage are shown in Figs. 13a-d for week 1 to week 4 forecast respectively. As it is seen from Fig. 12a most of the met-subdivisions over the south peninsula, central India and north-western parts of India show higher percentage of correct forecast (> $60 \%)$ with lower skill 
$(\leq 40 \%)$ over the four Met subdivisions viz., Vidarbha; East Madhya Pradesh; East Uttar Pradesh; and Nagaland, Manipur, Mizoram \& Tripura (Sub divisions no. 26, 20, 10 and 4 in Fig. 11a respectively) with remaining parts the correct category is between 40 to $60 \%$ (Fig. 12a). The week 1 forecast under the partially correct (PC) categories show highest value ( $>50 \%)$ for the met subdivision east Madhya Pradesh (Sub div no. 20 in central CEl in Fig. 11a) followed by the values between 30 to $50 \%$ over the other five met-subdivisions of central India including met-subdivision no 19,22, 25, 26 and 27; three subdivisions over the NWI including the subdivisions no. 10,11 and 15 and all the 7 met-subdivisions over the NEI shown in Fig. 11a. The lower values $(<30 \%)$ of partial categories are found in the remaining metsubdivisions over the eastern coastal regions, northwest India and western coastal parts of India (Fig. 12b). With regard to the week 1 forecast in the wrong categories (Fig. 12c) it is mainly below $20 \%$ over most of the sub-divisions except Vidarbha and east Rajasthan (Sub div no. 26 and 18 in Fig. 11a). The same can also been seen in Fig. 13a with decreasing order of correct \% categories, which can also be seen from Fig. 13a with 6 meteorological subdivisions viz., J \& K, West Rajasthan, Gujarat, Madhya Maharashtra, Tamil Nadu \& Pondicherry and North Interior Karnataka (Sub divisions no 16, 17, 21, 24, 31 and 33 in Fig. 11a) indicating correct categories of higher than 70\% with lowest being the sub-divisions Vidarbha (No. 26 in Fig. 11a) with $33 \%$.

Similarly, the week 2 forecast as shown in Fig. 12b indicated most of the sub-divisions with correct to partially correct categories between $30-50 \%$, whereas subdivisions over northwest India indicated slightly lower percentage ( $<20 \%)$. Similarly, the wrong categories in week 2 are up to $30 \%$ except some metsubdivisions over northwest India (No. 18, 13, 11 and 8 in Fig. 11a) also exceeding 30\%. It is also seen from Fig. 13b that except met subdivision J \& K and Himachal Pradesh (Sub division no. 16 and 15 in Fig. 11a) the correct percentage for met subdivisions are less than $70 \%$ with lowest being the west Uttar Pradesh (Sub division no 11 in Fig. 11a) with 17\%. It is also seen from Fig. 12b and Fig. 13b that in week 2 forecast the lower \% of partially correct categories ( $<30 \%)$ are mainly seen over north, north-western and south-eastern coastal states of India and higher values over the remaining regions. Comparing the week 1 and week 2 forecast in Fig. 12a and Fig. 12b it is seen that the partially correct \% are indicated almost identical like the correct \% categories in week 2 forecast, whereas in week 1 forecast it is dominated with higher values of correct \% over many subdivisions of India.

When the week 3 and week 4 forecasts are considered, the higher values are dominated with partially correct categories over most of the met-subdivision followed by the correct categories (Figs. 12c-d \& Fig. $13 \mathrm{c}-\mathrm{d})$. It is also seen from Fig. $13 \mathrm{c}$ that the correct categories week 3 forecasts show much higher values (>50\%) over some met-subdivisions of India such as Himachal Pradesh, Arunachal Pradesh, Odisha, Saurashtra \& Kutch (Subdivisions division no. 15, 2, 7, 22 and 31 in Fig. 11a respectively). Similarly, in case of week 4 forecast the correct categories show much higher values $(\approx 50 \%)$ over the three metsubdivisions viz., Himachal Pradesh, J \& K and Saurashtra \& Kutch (Subdivisions division no. 15, 16 and 22 in Fig. 11a respectively). Thus, the above analysis indicated that the categories forecasts at meteorological subdivisions show skilful result for applications in Agriculture planning, where it is not the quantum of rainfall that is important but the category forecast can also give useful inputs for Agricultural advisories. It may be mentioned here that the soil moisture along with precipitation and temperature 
anomalies can play a major role to estimate the agricultural and hydrological droughts severity and areal extent (Saha and Mishra 2017; Pattanaik et al., 2019).

\subsection{Met-subdivision level forecast for weak to active transition in July-August 2020.}

The skilful prediction of transitions from active to break and vice versa is very significant for providing services to agricultural sector. With regard to the excess monsoon year of 2020 there was a relatively weak spell of monsoon during most of July and it revived during August leading to very active phase of monsoon in August (Fig. 2). The daily average rainfall ( $\mathrm{mm}$ ) over the Monsoon Zone of India (MZI) as demarcated in Fig. 11a during monsoon season 2020 from June to September along with the corresponding standardized rainfall anomalies over is shown in Fig. 14a-b. The MZI is defined based on the significant correlation with all India monsoon rainfall and is being used as the active break cycle of monsoon based on the standardized rainfall anomalies (Rajeevan et al. 2010). This is also reflected in Fig. 14a-b with daily rainfall over monsoon core region indicated below normal rainfall during last week of July and gradual improvement of rainfall condition in first week of August and becoming above normal rainfall during remaining parts of August. Since the met-subdivision level forecasts are being used for Agriculture the observed rainfall departure for 4 weeks (24 July to 20 August) indicating this transition from weak monsoon to active monsoon can be seen from Figs. 15a with many sub-divisions indicating below normal rainfall mainly over northwest India and adjoining central India during 24-30 July and gradually becoming above normal rainfall over most parts of India in subsequent three weeks (Fig. 15b-d). The 4 weeks category forecast of rainfall from 24 July to 20 August based on the initial condition of 22 July and valid for the same period is shown in Figs. 16a-d also indicated the weak to active transition of monsoon very well. The weak to normal transition of monsoon during two weeks period from 24-30 July and 31 July-06 August, 2020 is demonstrated for met-subdivision level forecast. As seen from Fig. 16a-b most of the meteorological subdivisions in northwest India changed from below normal category in week 1 forecast to normal category in week 2 forecast. Over southern peninsula the above normal category in week 1 forecast remains above normal in week 2 forecast also. Based on this met-subdivision level forecast the agro-advisory is issued to farmers, which is found to be very useful for agricultural applications as already discussed by Chhatopadhyaya et al. (2018). The skill in terms of correct (C), partially correct (PC) and wrong (W) forecast for the 36 subdivisions for this episode during the entire monsoon season of 2020 is shown in Fig. 17. As seen in Fig. 17 the correct percentage gradually decreases an is $58 \%$ for week 1 forecast, $44 \%$ for week 2 forecast, $3853 \%$ for week 3 forecast and $56 \%$ for week 4 forecast, which is slightly higher than the mean forecast skill of monsoon 2020 shown in Fig. 11b. It is also seen from Fig. 17 that the partial correct category also indicated much higher values week 2 forecast followed by week 1 \& week 3 and finally week 4 forecasts. With regard to wrong forecast is about $6 \%$ in week 1 and week 2 forecasts and about $11 \%$ in week 3 and week 4 forecast. Further, it is to be mentioned here that the district level forecasts will be more useful to farmers considering the size of a met-subdivision as comparatively big. Considering this IMD has also started preparing the district level category forecasts experimentally both in terms of 3 categories (Normal, Below Normal and Above Normal based on the rainfall departure as given in right column in Table 1). It is also 
proposed to prepare the districts level forecast of two weeks in near future for the agro-advisory purposes in the real-time in the category forecasts case, which is expected to provide useful services to the farming community over more than 650 districts of India.

\section{Summary Of The Main Results}

IMD's operational ERF based on CFSv2 coupled modelling system was evaluated at different spatial scales starting from All India to 36 meteorological subdivision level for 2020 monsoon season. The hindcast run for 17 years (2003 to 2019) along with the operational run for 2020 monsoon season was carried out with every Wednesday initial conditions and the forecast is generated for 4 weeks starting from subsequent Friday to Thursday and so on. The operational ERF could capture the early onset of monsoon over the Bay of Bengal and normal onset of monsoon over the southern tip of India. The ERF also captured the relatively fast progress of monsoon northward after the onset, relatively weak monsoon conditions in July and also its transition into active monsoon conditions in August, active second half of September and delayed withdrawal of monsoon with a lead time of about 2 to 3 weeks. Quantitatively, over the country as a whole the ERF forecast provided useful guidance with the CC between observed and forecast rainfall departure is found to be significant till three weeks.

The spatial distribution of met-subdivision level mean forecast skill of predicting Above normal, normal and below normal categories in terms of correct (C) forecast (forecast and observed category matching) for the 36 subdivisions during the entire monsoon season of 2020 is gradually decreased and is $58 \%$ for week 1 forecast, $45 \%$ for week 2 forecast, 38\% for week 3 forecast and 34\% for week 4 forecast. When the correct and partially correct forecasts (when the forecast category is out by one category) are combined together, it becomes $89 \%$ in week 1 forecast, $83 \%$ in week 2 forecast, $80 \%$ in week 3 forecast and $78 \%$ in week 4 forecast, which is found to be very skilful for issuing the agro-advisories to farmers. Thus, the wrong category forecast is found to be between 11 to $22 \%$ in week 1 to week 4 forecasts. Considering the encouraging results of met-subdivision level forecast the same are being used operationally for agrometeorological services for the farming communities of India.

\section{Declarations}

\section{Conflict of Interest}

The authors declare that they have no conflict of Interests.

\section{Ethics approval}

This paper is not submitted to any other journal for publication.

\section{Consent for publication}

All the authors have consented to publish this research. 


\section{Funding Statement}

There is no funding support for the current research. Thus, it is not applicable in this case.

\section{Author's Contribution}

All authors contributed to the study. D. R. Pattanaik (DRP), and R. Phani (RP) conceptualised the idea for current research and set up the design for the study. XXXX performed the model setup, simulations, and evaluation. Data processing and further analysis were done by Ashish Alone, Praveen Kumar, Raju Mandal and Avijit Dey. DRP and RP wrote the first draft of the manuscript. All authors read and agreed with the final manuscript.

\section{Acknowledgement}

We are thankful to Dr. M. Mohapatra, Director General, India Meteorological Department for providing all supports in carrying out this research work. The real time extended range forecast capability of IMD is being strengthened through the collaborative efforts of the MoES institutions viz., the IITM, NCMRWF, INCOIS and NCEP. The CFSv2/GFSbc customised at ITTM was implemented in IMD for the operational run. Thanks are due to IMD Pune for providing observed rainfall data. Thanks to Dr. A. K. Sahai for valuable support provided from ERF group, IITM, Pune.

\section{References}

1. Chattopadhyay N, Rao KV, Sahai AK, et al (2018) Usability of extended range and seasonal weather forecast in Indian agriculture. Mausam 69:29-44. https://mausamjournal.imd.gov.in/index.php/MAUSAM/article/view/218

2. Chattopadhyay, N., Bhowmik, S. K. Roy, Singh, K. K., Ghosh, K. and Malathi, K., (2016) "Verification of district level weather forecast". Mausam 67:829-840.

3. Gadgil Sulochana and Siddhartha Gadgil, 2006 : The Indian Monsoon, GDP and agriculture. Economic and Political Weekly, Vol. 41, No. 47, Nov. 25 - Dec. 1, 2006, DOI: 10.2307/4418949. (Accessed on Jan 2021 https://www.jstor.org/stable/4418949).

4. India Meteorological Department (IMD), 2020 : End of monsoon season report 2020. Accessed Jan 2021 (https://mausam.imd.gov.in/imd_latest/contents/season_report.php)

5. Krishnan R, Zhang C, Sugi M (2000) Dynamics of breaks in the Indian summer monsoons. J Atmos Sci 57:1354-1372. https://doi.org/10.1175/1520-0469(2000)057<1354:DOBITI>2.0.C0;2

6. Madden R, Julian P (1971) Detection of a 40-50 day oscillation in the zonal wind in the tropical Pacific. J Atmos Sci 28:702-708. https://doi.org/10.1175/15200469(1971)028<0702:DOADOI>2.0.CO;2

7. Mitra AK, Bohra AK, Rajeevan MN, Krishnamurti TN (2009) Daily Indian precipitation analysis formed from a merge of rain-gauge data with the TRMM TMPA satellite-derived rainfall estimates. $J$ Meteorol Soc Jpn Ser II, 2009 87A:265-279. https://doi.org/10.2151/jmsj.87A.265 
8. Pattanaik DR Kumar A (2014) Comparison of intra-seasonal forecast of Indian summer monsoon between two versions of NCEP coupled models. Theor Appl Climatol 118 : 331345. https://doi.org/10.1007/s00704-013-1071-1

9. Pattanaik DR (2003) The northward moving low frequency mode : A case study of 2001 monsoon season. Mausam 54:937-940. https://metnet.imd.gov.in/mausamdocs/25444.pdf

10. Pattanaik DR (2014) Meteorological subdivisional-level extended range forecast over India during southwest monsoon 2012. Meteorol Atm Phys 124:167-182.https://doi.org/10.1007/s00703-0140308-6

11. Pattanaik DR, Rathore LS, Kumar Arun (2013) Observed and Forecasted Intraseasonal Activity of Southwest Monsoon Rainfall over India during 2010, 2011 and 2012. Pure appl Geophys 170:23052328.https://doi.org/10.1007/s00024-013-0670-1

12. Pattanaik DR, Sahai AK, Muralikrishna RP, Mandal R and Dey A (2020) : Active-Break Transitions of Monsoons Over India as Predicted by Coupled Model Ensembles. Pure appl Geophys 177:43914422. https://doi.org/10.1007/s00024-020-02503-2

13. Pattanaik DR, Sahai AK, Mandal R, Muralikrishna PR, Dey A, Chattopadhyay R, Joseph S, Tiwari AD, Mishra V(2019) Evolution of operational extended range forecast system of IMD: Prospects of its applications in different sectors, Mausam 70:233-

264. https://mausamjournal.imd.gov.in/index.php/MAUSAM/article/view/170/123

14. Rajeevan M, Gadgil S, Bhate J (2010) Active and break spells of the Indian summer monsoon. J Earth Sys Sci 119:229-247. https://www.ias.ac.in/article/fulltext/jess/119/03/0229-0247

15. Rathore LS, Bhowmik SKR, Chattopadhyay N (2011) Integrated Agrometeorological Advisory Services in India. In: Attri S., Rathore L., Sivakumar M., Dash S. (eds) Challenges and Opportunities in Agrometeorology. Springer, Berlin, Heidelberg. https://doi.org/10.1007/978-3-642-19360-6_14

16. Regional Specialised Meteorological Centre (RSMC) 2020 Report On Cyclonic Disturbances Over North Indian Ocean During (2020) India Meteorological Department, New Delhi, PP;1-347.. Accessed Jan 2021 from http://www.rsmcnewdelhi.imd.gov.in/uploads/report/27/27_6f8db1_rsmc-2020.pdf.

17. Robertson AW, Acharya N, Goddard L, Pattanaik DR, Sahai AK, Singh KK, Ghosh K, Agarwal A, Buizer JL (2019) Subseasonal forecasts of the 2018 Indian Summer Monsoon over Bihar. J. Geophys. Res. (Atmosphere) 124:13,861-13,875.

18. https://doi.org/10.1029/2019JD031374

19. Saha S, Moorthi S, Wu X, Wang J, Nadiga S, Tripp P, Pan HL, Behringer D, Hou YT, Chuang HY, Iredell M, Ek M, Meng J, Yang R, Van den DH, Zhang Q, Wang W, Chen M (2014) The NCEP Climate Forecast System Version 2. J Clim 27:2185-2208. http://dx.doi.org/10.1175/JCLI-D-12-00823.1

20. Sahai AK, Chattopadhyay R, Joseph S, Mandal R, Dey A, Abhilash S, Muralikrishna RP, Borah N (2015) Real-time performance of a multi-model ensemble-based extended range forecast system in predicting the 2014 monsoon season based on NCEP-CFSv2.Curr Sci 109:1802-1813.

https://www.jstor.org/stable/24906143 
21. Sahai AK, Sharmila S, Abhilash S, Chattopadhyay R, Borah N, RPM Krishna, Joseph S, Roxy M, De S, Pattnaik S, Pillai PA (2013) Simulation and extended range prediction of monsoon intra-seasonal oscillations in NCEP CFS/GFS version 2 framework. Curr Sci 104:1394-

1408. https://www.jstor.org/stable/24092513

22. Sharma A (2015) National Council of Applied Economic Research, "Report on "Economic benefits of Dynamic weather and ocean information and advisory services in India and cost prising of customized products and services of ESSO-NCMRWF \& ESSO-INCOIS.

23. Sikka DR, Gadgil S (1980) On the maximum cloud zone and the ITCZ over India longitude during the southwest monsoon. Mon Weather Rev 108:1840-1853. https://doi.org/10.1175/15200493(1980)108<1840:OTMCZA>2.0.C0;2

24. Suhas E, Neena JM, Goswami BN (2013) An Indian monsoon intraseasonal oscillations (MISO) index for real time monitoring and forecast verification. Climate Dynamics 40: 2605-2616. https://doi.org/10.1007/s00382-012-1462-5.

25. Tyagi A, Pattanaik DR (2010) Real Time Monitoring and Forecasting of Intra-Seasonal Monsoon Rainfall Activity over India During 2009. IMD Met. Monograph, Synoptic Met. No.10/2010, 1-45.

26. Wheeler M, Hendon H (2004) An All-Season Real-Time Multivariate MJO Index: Development of an Index for Monitoring and Prediction. Mon Weather Rev 132:1917-

1932. https://doi.org/10.1175/1520-0493(2004)132<1917:AARMMl>2.0.C0;2

27. Yasunari T (1979) Cloudiness fluctuation associated with the Northern Hemisphere summer monsoon. J Meterol Soc Jpn 5:227-242. https://doi.org/10.2151/jmsj1965.57.3_227

\section{Figures}

\begin{tabular}{|c|c|c|c|}
\hline Model Runs & $\begin{array}{c}\text { Onset Phase } \\
\text { ICs used from } \\
\text { (GDAS \& GODAS) }\end{array}$ & $\begin{array}{c}\text { Active/Break Phase } \\
\text { ICs used from } \\
\text { (GDAS \& GODAS) }\end{array}$ & $\begin{array}{l}\text { Withdrawal Phase } \\
\text { ICs used from } \\
\text { (GDAS \& GODAS) }\end{array}$ \\
\hline $\begin{array}{l}\text { - Operational run for } \\
2020 \text { Monsoon }\end{array}$ & $\begin{array}{l}\text { Apr : } 29 \\
\text { May : } 06,13,20,27 \\
\text { Jun : } 03,10,17,24\end{array}$ & $\begin{array}{l}\text { Jul : } 01,08,15,22,29 \\
\text { Aug : } 05,12,19,26\end{array}$ & Sep : $03,10,17,24$ \\
\hline $\begin{array}{l}- \text { Hindcast period for } \\
17 \text { years }(2003-2019)\end{array}$ & $\begin{array}{l}\text { Apr }: 29 \\
\text { May : } 06,13,20,27 \\
\text { Jun : } 03,10,17,24\end{array}$ & $\begin{array}{l}\text { Jul : } 01,08,15,22,29 \\
\text { Aug : } 05,12,19,26\end{array}$ & Sep : $03,10,17,24$ \\
\hline $\begin{array}{l}\text { - Models used with } \\
\text { ensemble members }\end{array}$ & $\begin{array}{l}\text { CFSv2 T382 (4) } \\
\text { CFSv2 T126 (4) } \\
\text { GFSbc T382 (4) } \\
\text { GFSbc T126 (4) }\end{array}$ & $\begin{array}{l}\text { CFSv2 T382 (4) } \\
\text { CFSv2 T126 (4) } \\
\text { GFSbc T382 (4) } \\
\text { GFSbc T126 (4) }\end{array}$ & $\begin{array}{l}\text { CFSv2 T382 (4) } \\
\text { CFSv2 T126 (4) } \\
\text { GFSbc T382 (4) } \\
\text { GFSbc T126 (4) }\end{array}$ \\
\hline
\end{tabular}


Figure 1

IMD’s Operational Extended Range Forecast (ERF) System for 2020 monsoon.

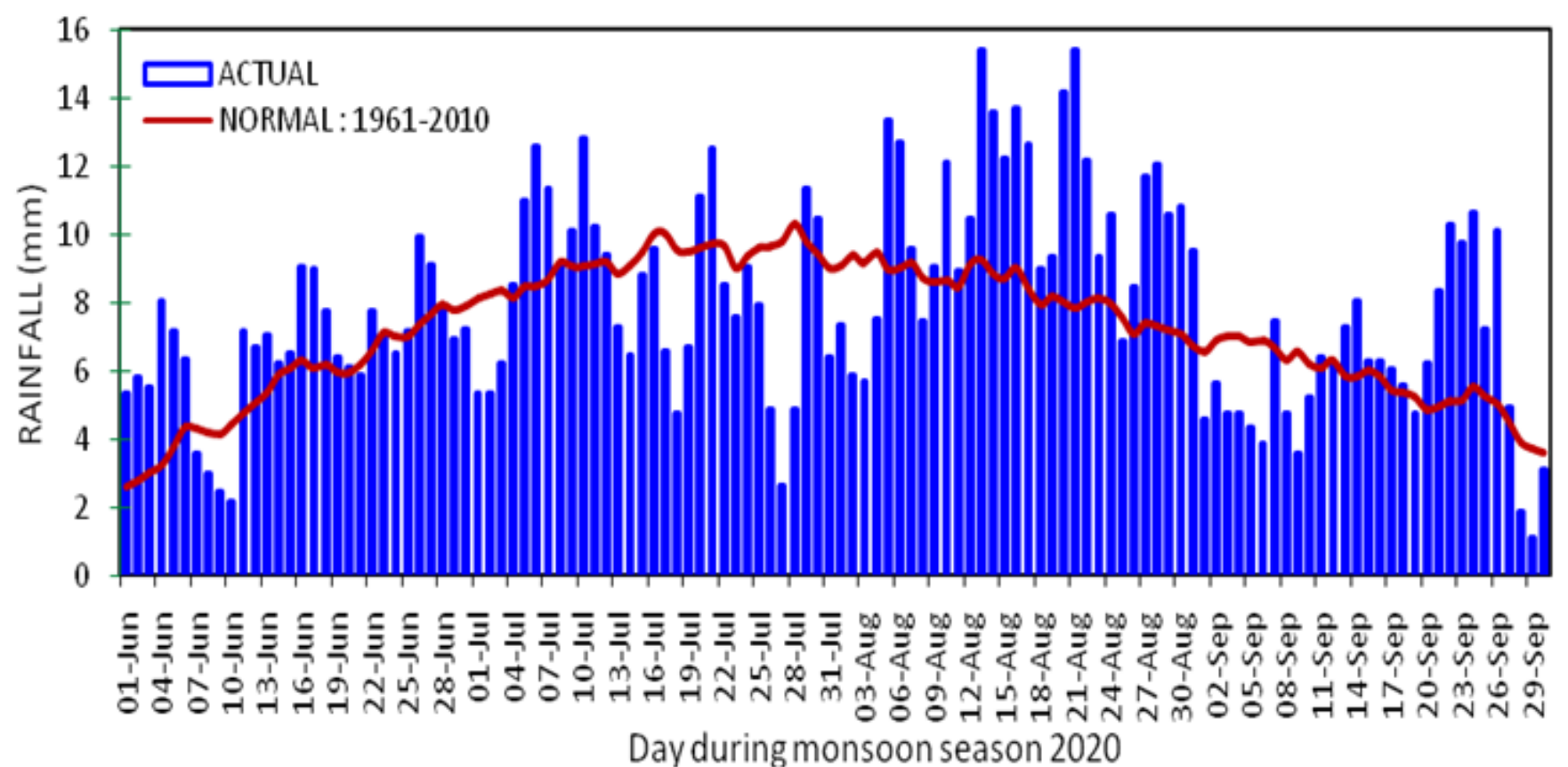

Figure 2

Daily actual and normal rainfall over India during monsoon season from June to September 2020 
(a)

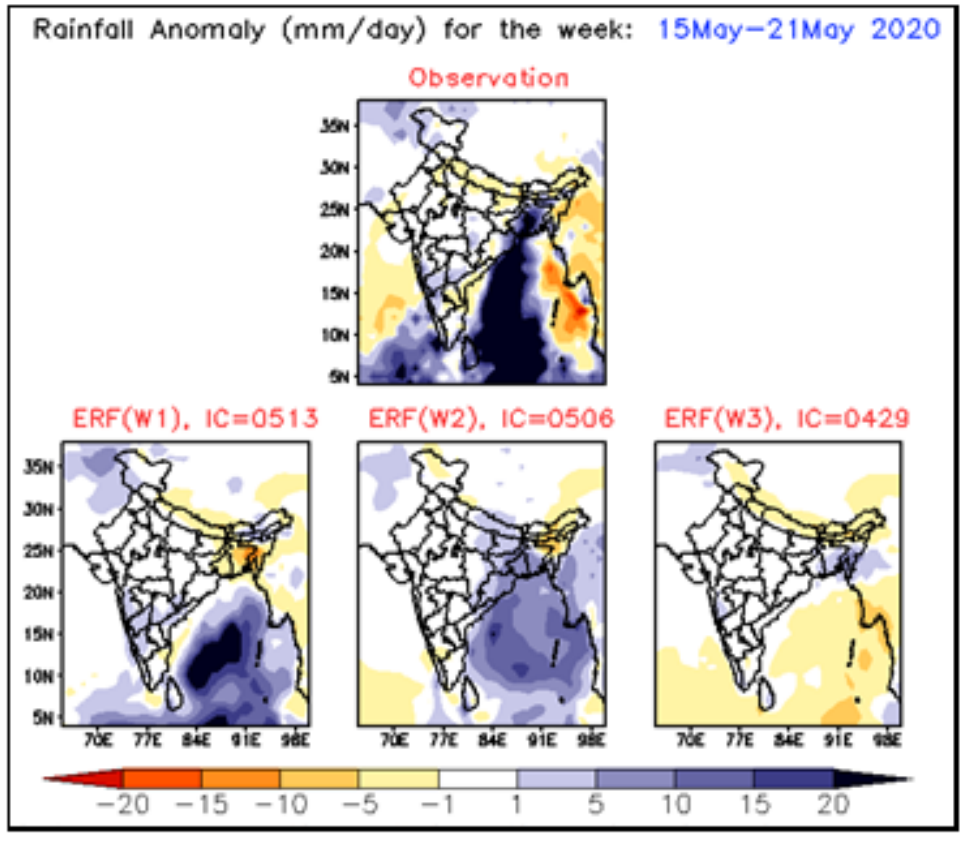

(b)

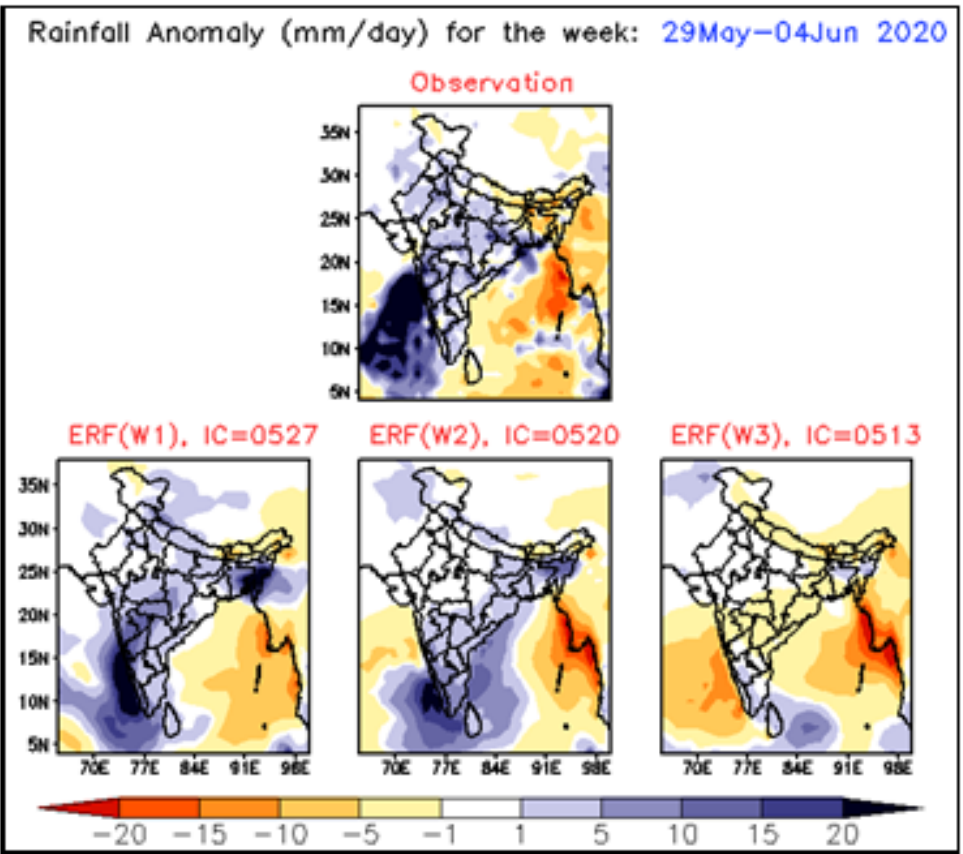

Figure 3

(a) Observed weekly rainfall anomaly for the period 15-21 May, 2020 and three weeks Extended Range Forecast rainfall anomaly for the same target week based on 13 May, 06 May and 29 April. (b) Same as 'a' but for the target week of 29 May-04 June 2020 and ICs of 27 May, 20 May and 13 May, 2020. 


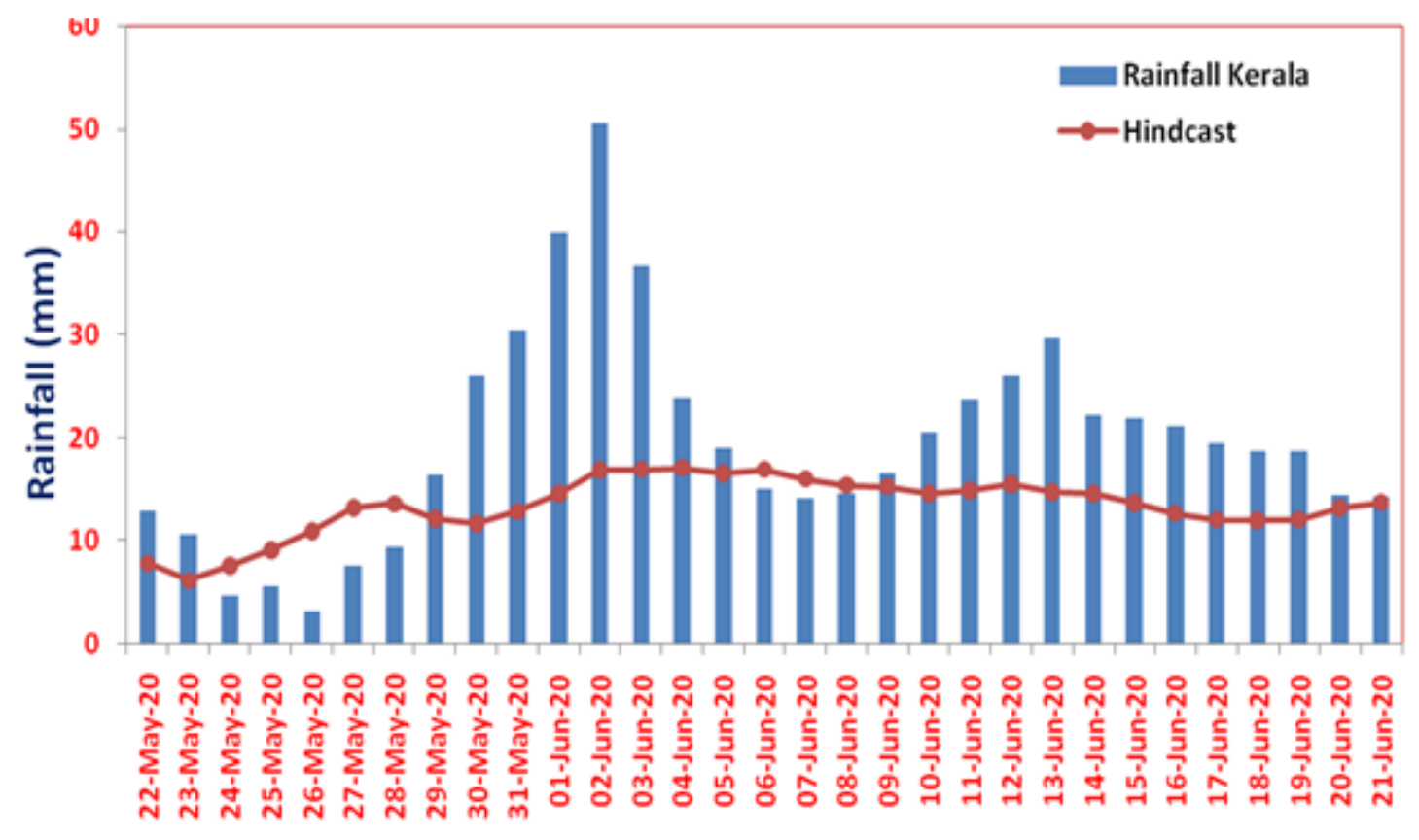

Date

\section{Figure 4}

The daily forecast rainfall for 2020 \& hindcast climatology rainfall time series over the Kerala coast averaged over 75-77.5E \& 8-10.5N based on IC of 20th May.

(a) Target week of 05-11 June, 2020

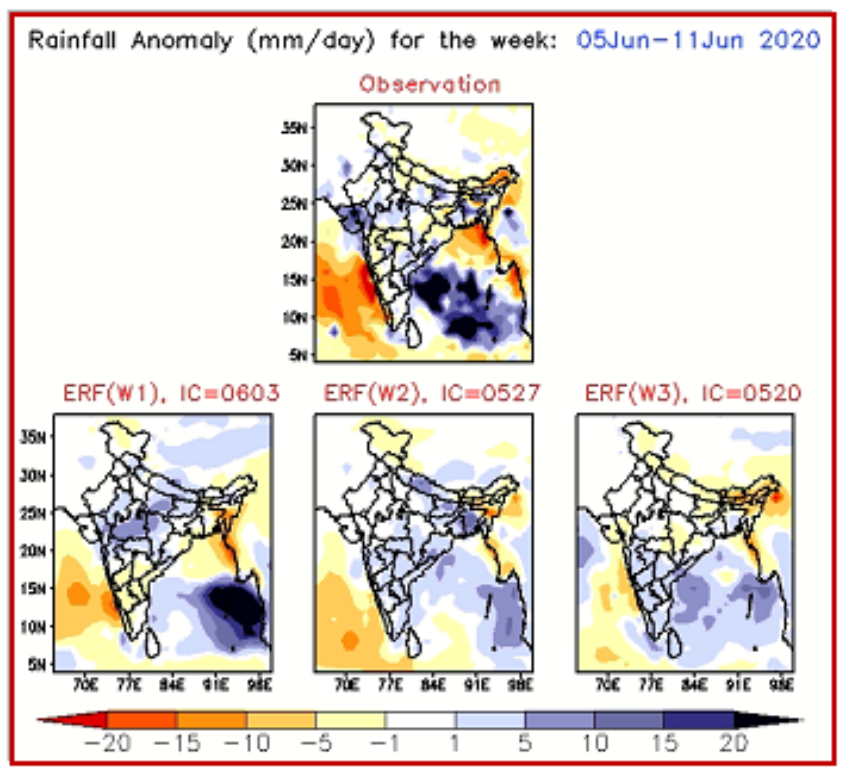

(b) Target week of 12-18 June, 2020

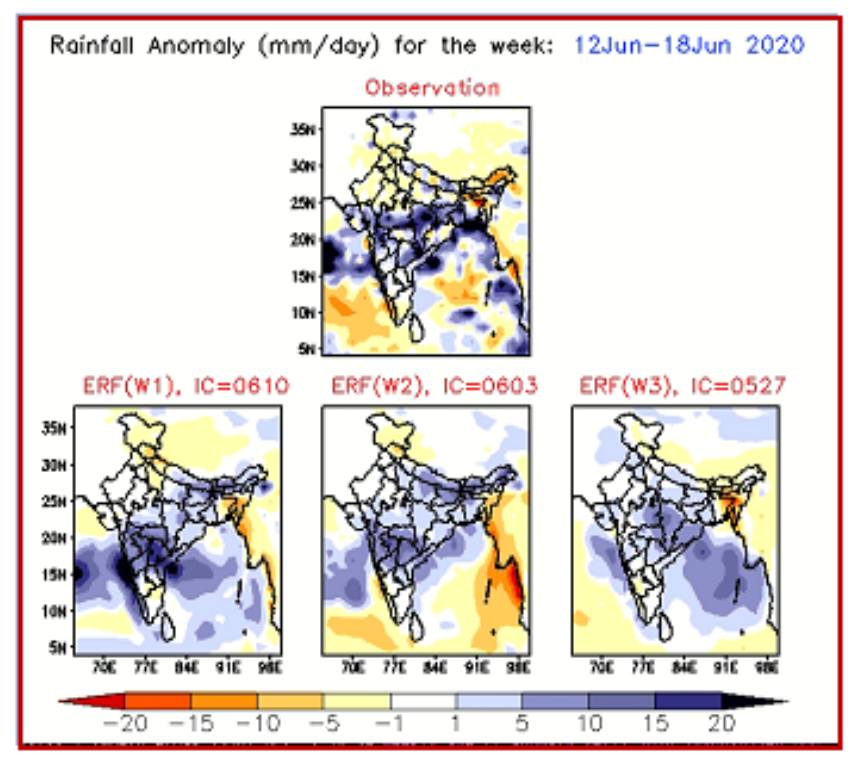

Figure 5 
(a) Observed weekly rainfall anomaly for the period 05-11 June 2020 and three weeks ERF rainfall anomaly for the same target week with ICs of 03 June, 27 May and 20 May. (b) Same as 'a' but for the target week of 12-18 June, 2020 with ICs of 10 June, 03 June and 27 May.

(a) Target week of 10-16 July, 2020

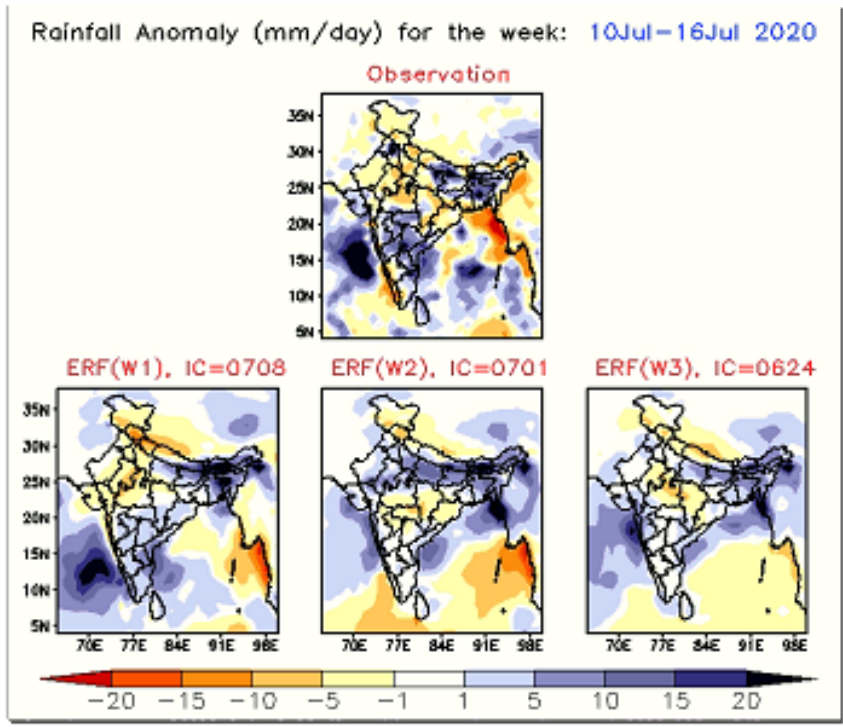

(c) Target week of 24-30 July, 2020

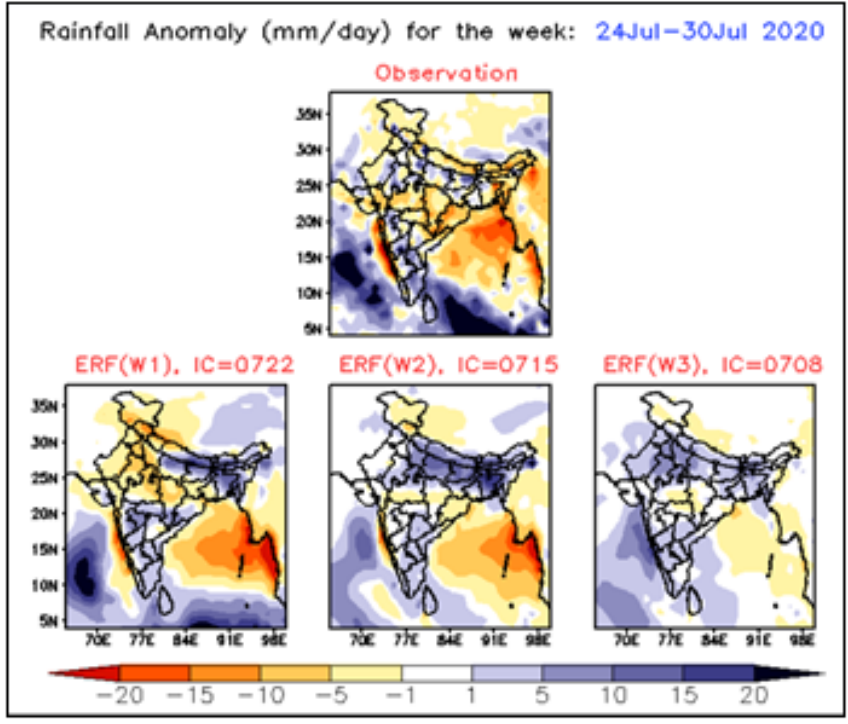

(b) Target week of 17-23 July, 2020

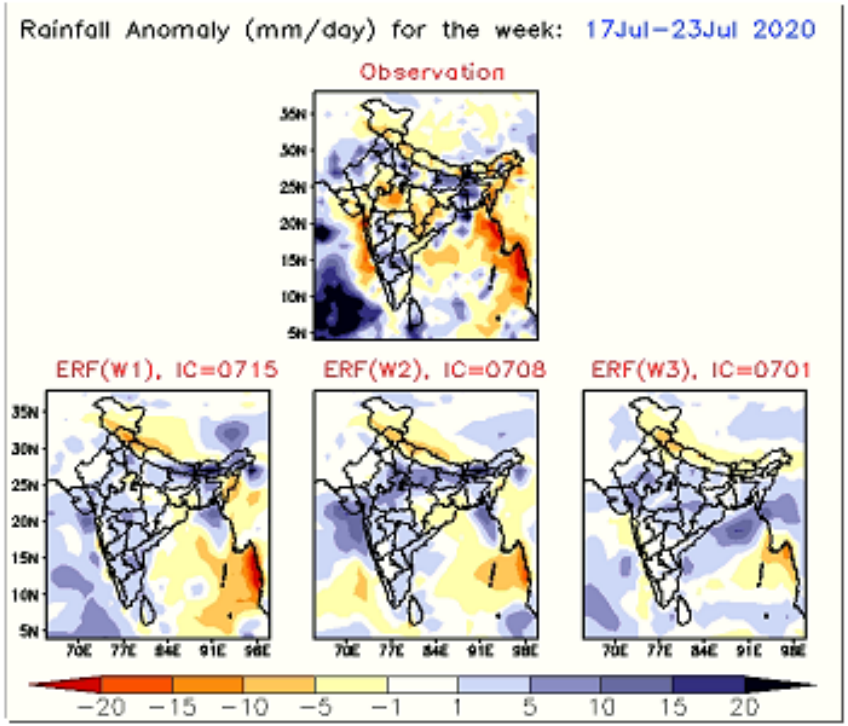

(d) MISO forecast based on 08 July, 2020

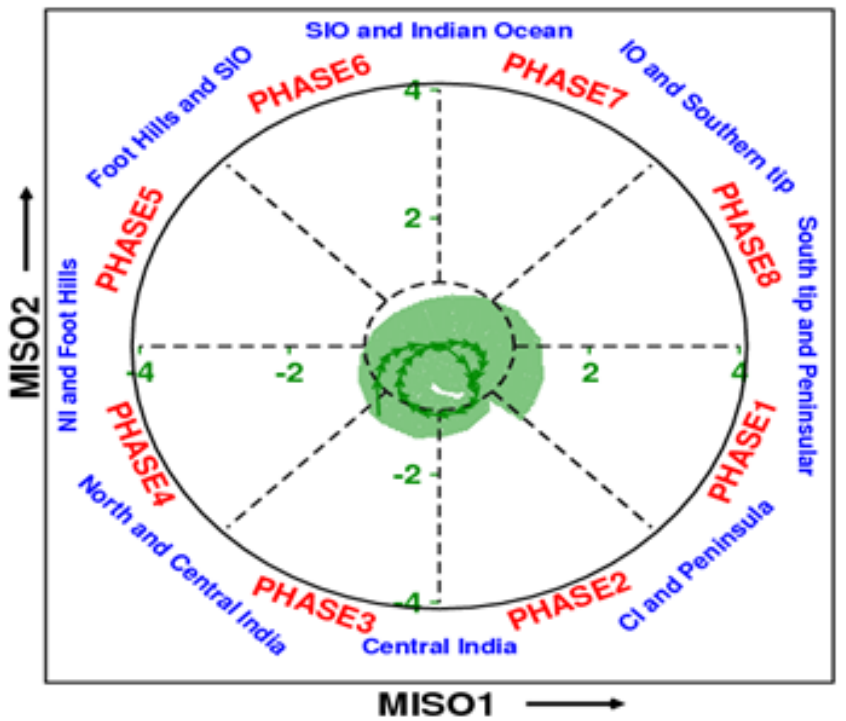

Figure 6

(a) Observed weekly rainfall anomaly for the period 10-16 July, 2020 and three weeks ERF rainfall anomaly for the same target week. (b) Same as 'a' but for the target week of 17-23 July (c) for the target week of 24-30 July and (d) ERF of MISO phase for 4 weeks based on IC of 08 July, 2020. 

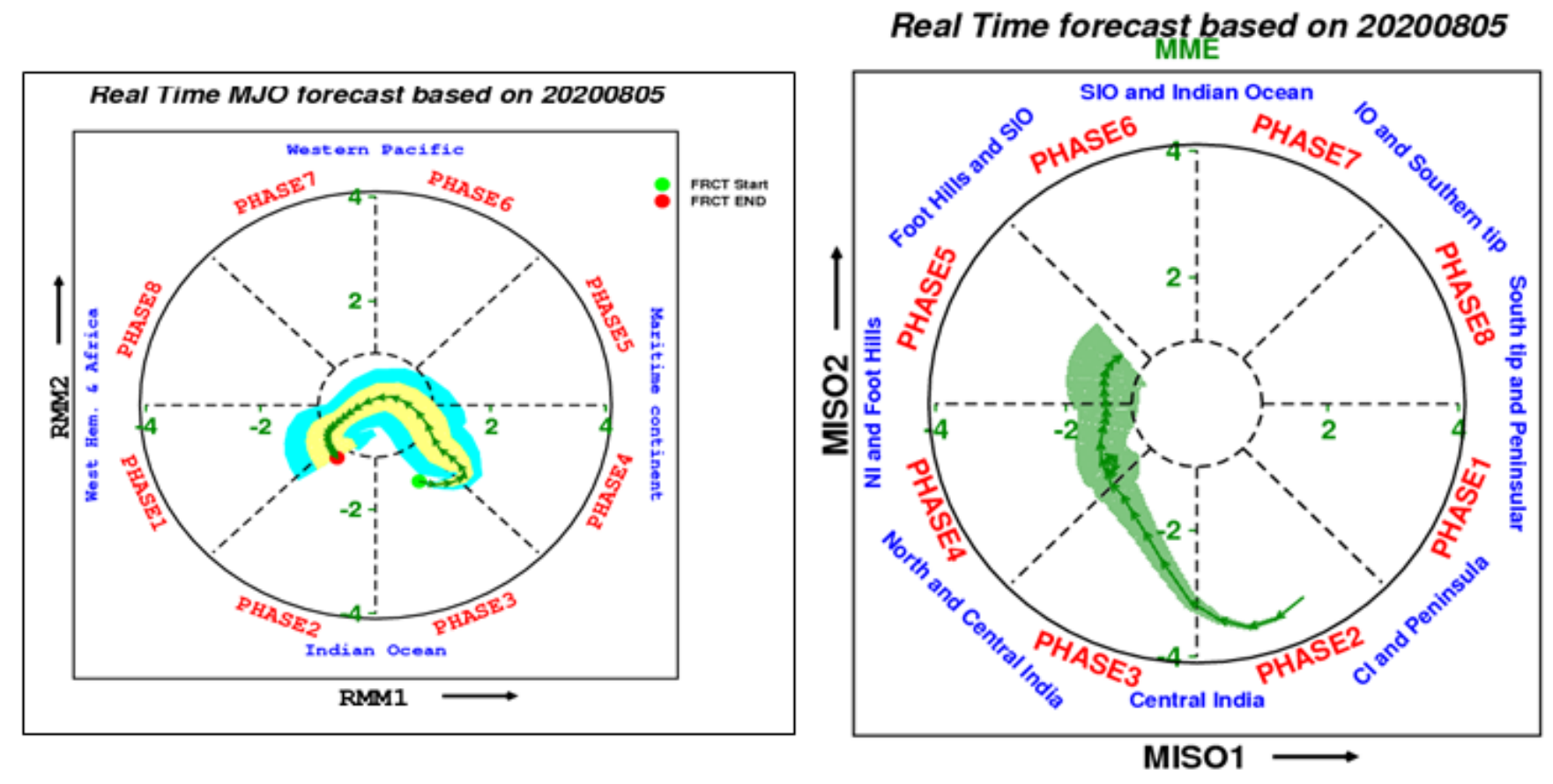

Figure 7

(a) Extended Range Forecast of MJO for 4 weeks based on 5th August, 2020 (b) Same as 'a' but for the ERF of MISO phase for 4 weeks. 
(a) Target week of 07-13 August, 2020

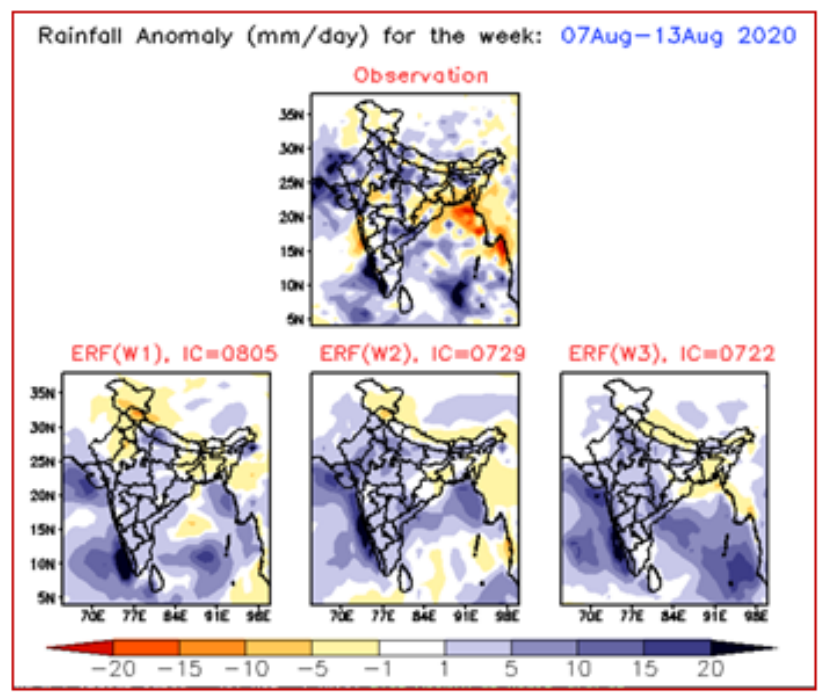

(b ) Target week of 14-20 August, 2020

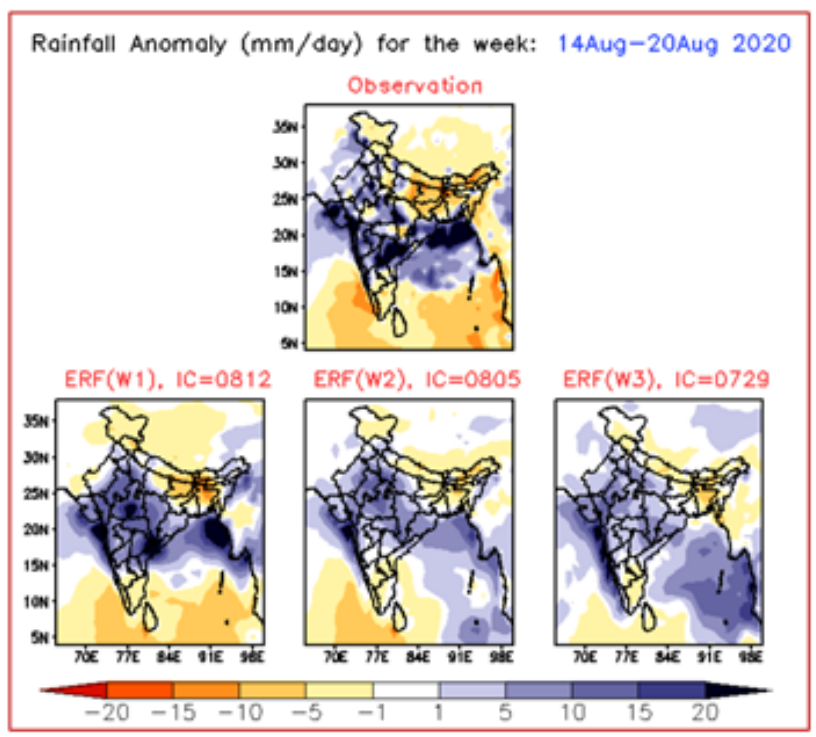

(c) Target week of 21-27 August, 2020

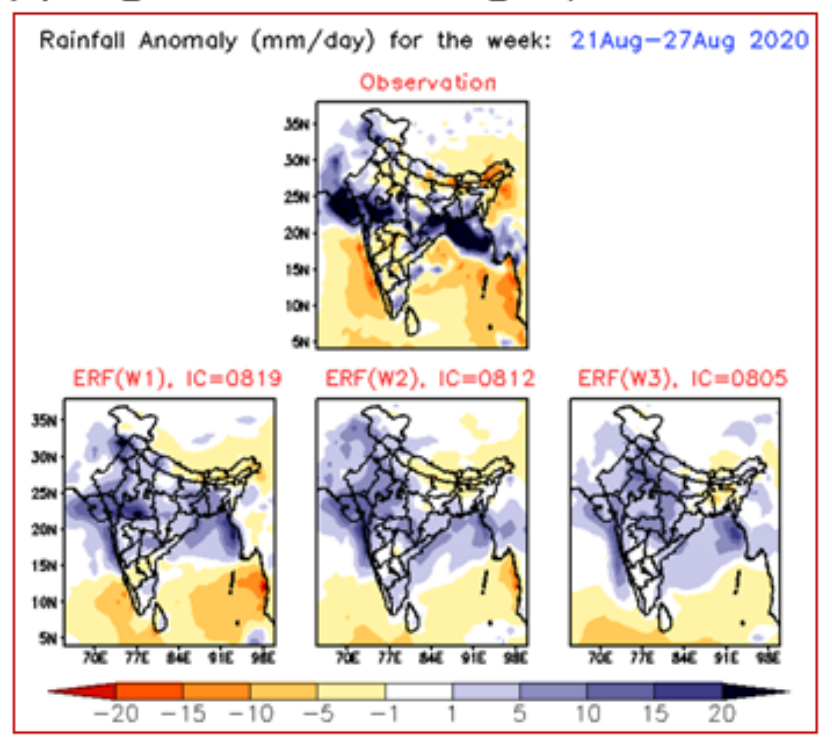

Figure 8

(a) Observed weekly rainfall anomaly for the period 07-13 August, 2020 and three weeks ERF rainfall anomaly for the same target week. (b) Same as 'a' but for the target week of 14-20 August and (c) for the target week of 21-27 August. 
(a) $850 \mathrm{hPa}$ wind, IC = $9^{\text {th }}$ Sep, 2020
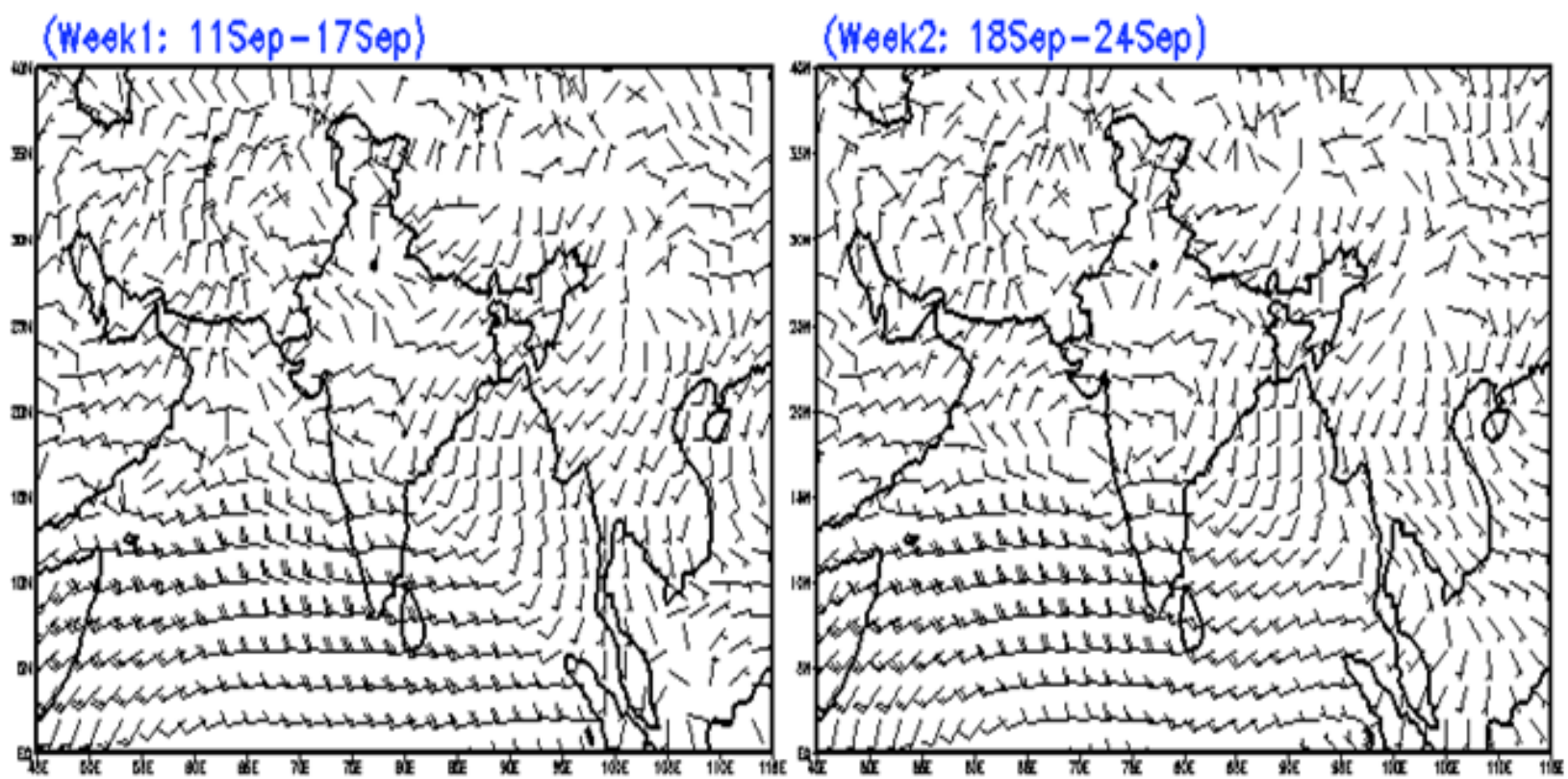

(b) Target week of 11-17 September, 2020

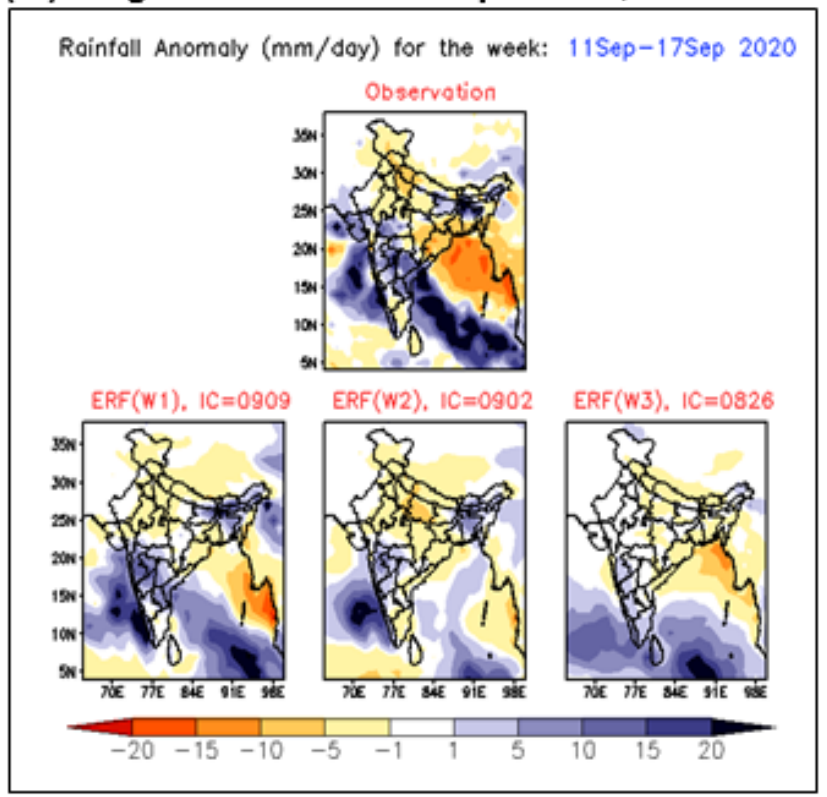

(c) Target week of 18-24 September, 2020

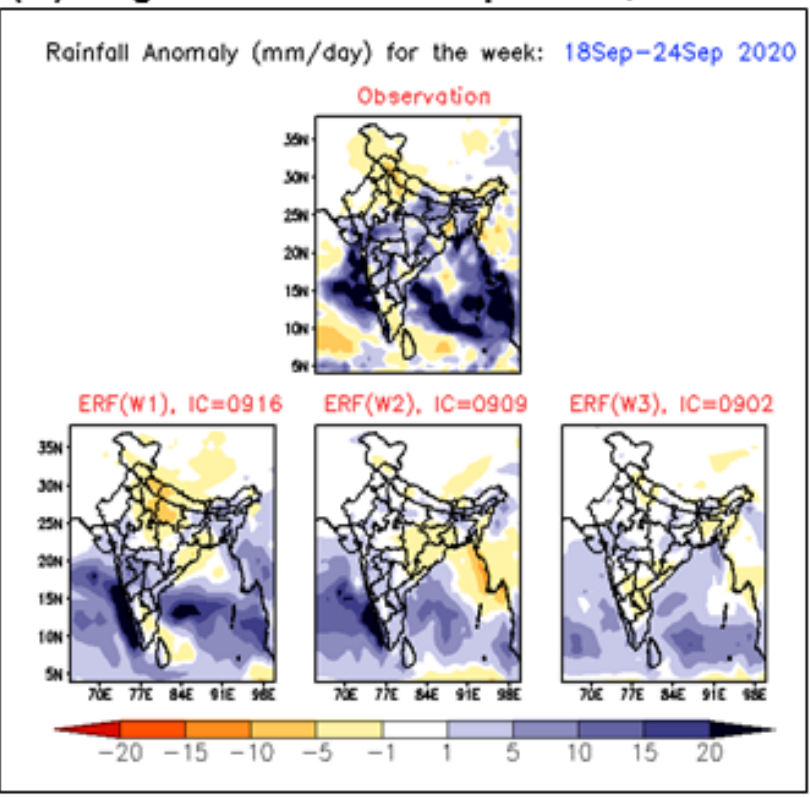

Figure 9

(a) Two weeks ERF of weekly $850 \mathrm{hPa}$ mean wind based on IC of 9th Sep, 2020. (b) Observed weekly rainfall anomaly for the period 11-17 Sep, 2020 and three weeks ERF rainfall anomaly for the same target week. (c) Same as 'b' but for the target week of 18-24 Sep, 2020. 


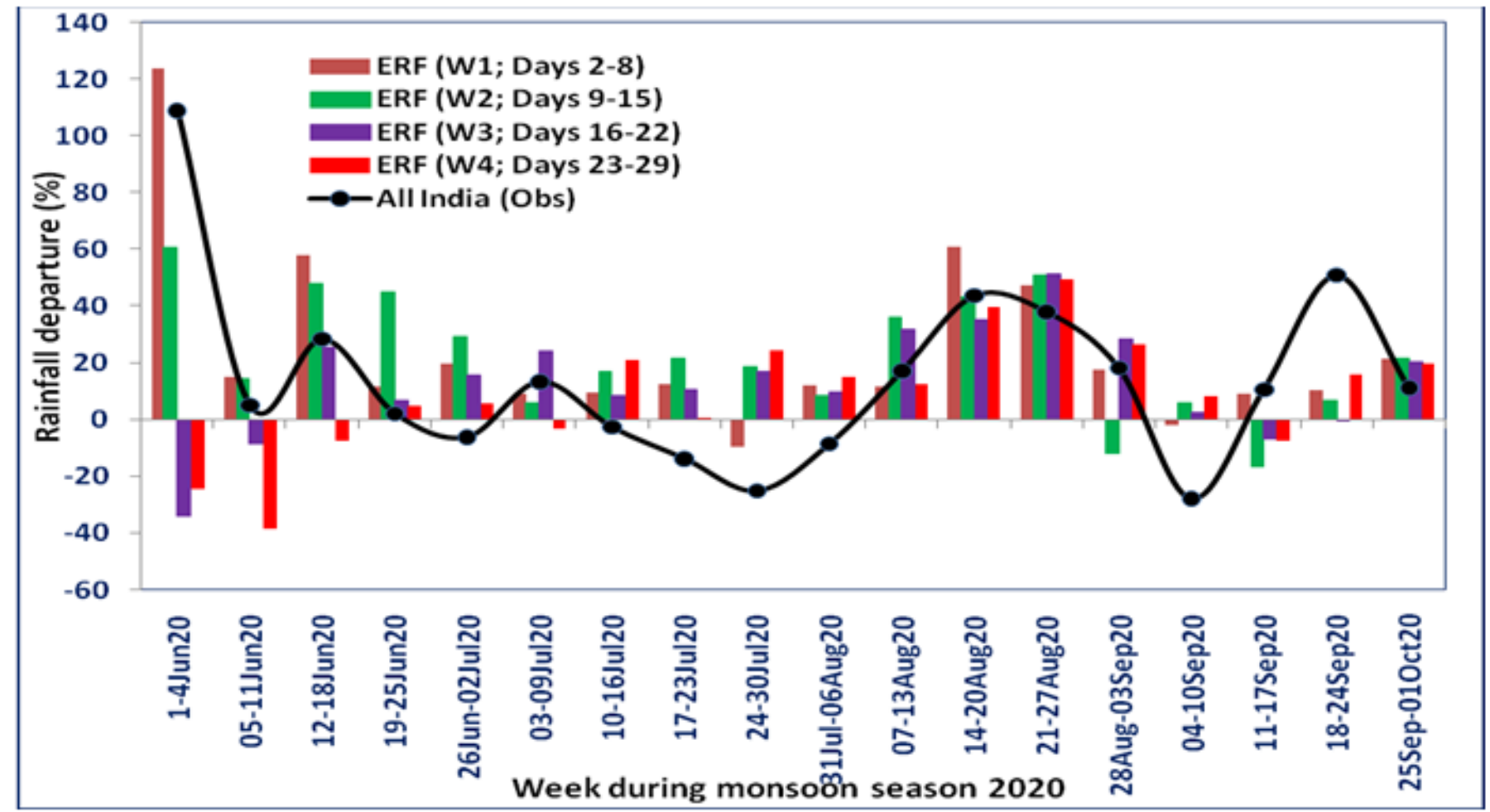

Figure 10

The observed and forecast rainfall valid for four weeks during the 2020 monsoon season from June to September. 
(a)
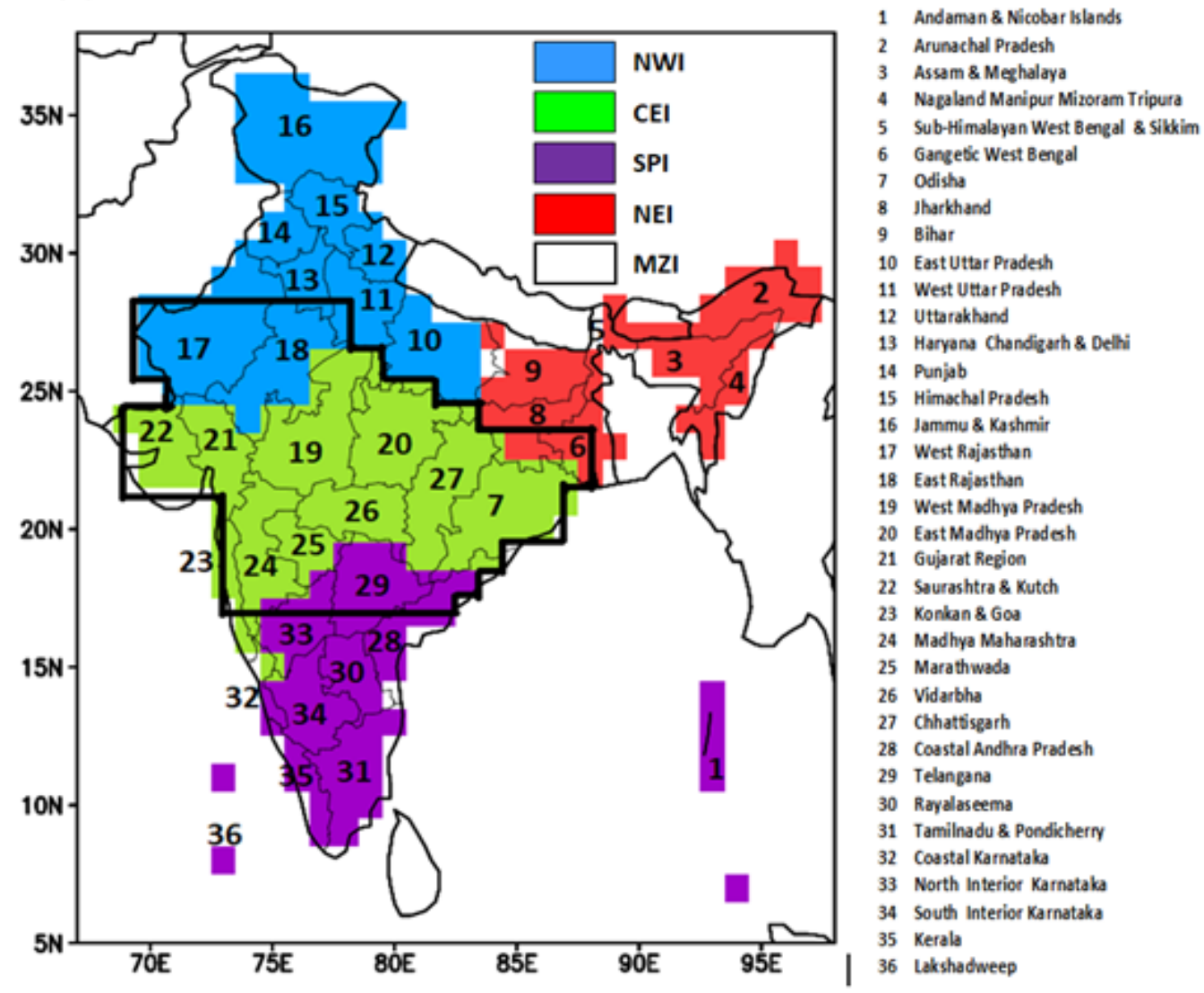

(b)

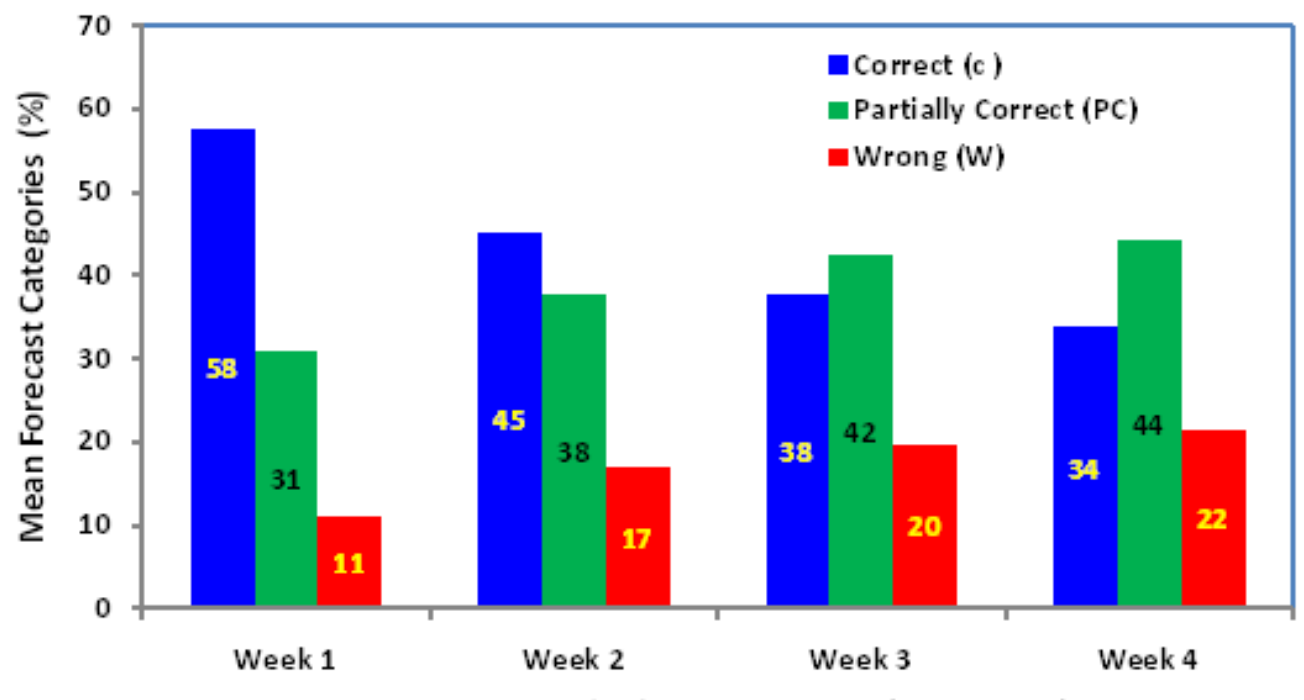

Forecast period of monsoon 2020 (Jun to Sep)

\section{Figure 11}

(a) Homogeneous regions of India, NEI - Northeast India, NWI - Northwest India, CEI - Central India, SPI South Peninsular India and MZI - Monsoon Zone of India along with 36 met subdivisions of India . (b) The verification skill score (in \%) of met-subdivision level forecast in terms of correct (C), partially correct (PC) and wrong (W) forecast during the monsoon season 2020. 
(a): Week 1 ( C)

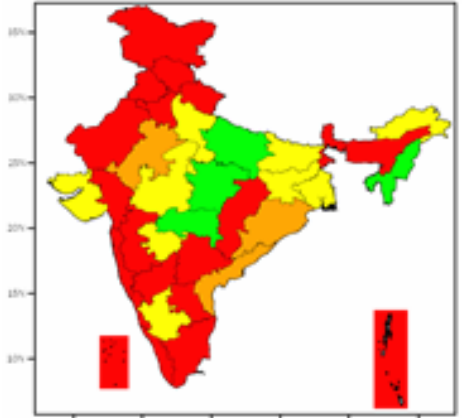

(d): Week 2 ( C)

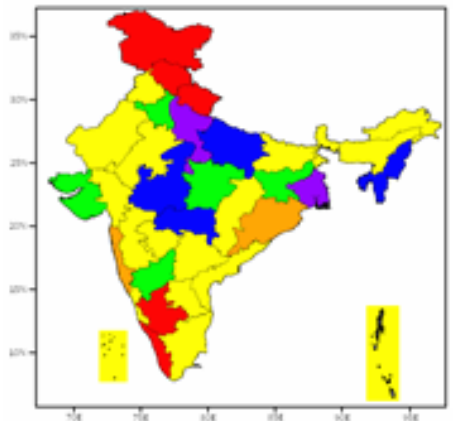

(g); Week 2 ( C)

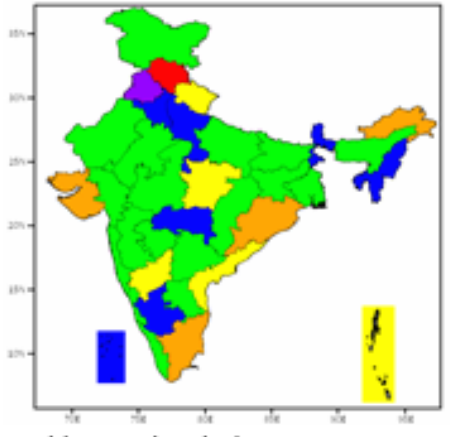

(j); Week 4 ( C)

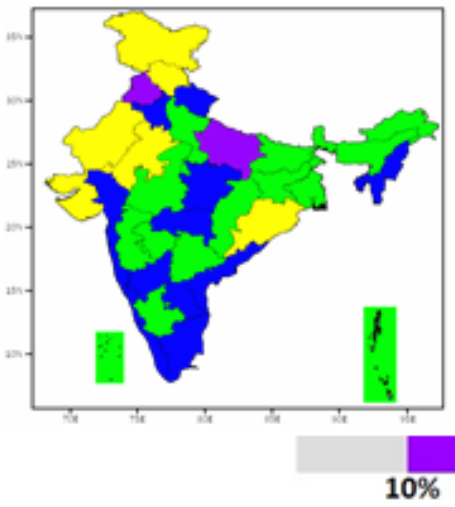

(b): Week 1 (PC)

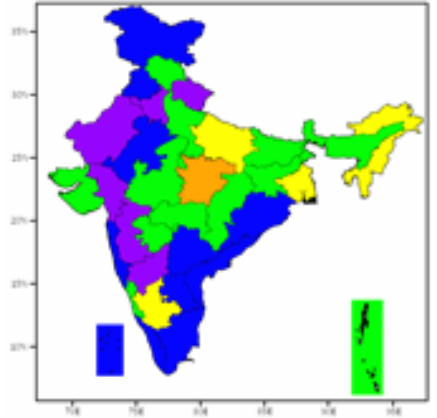

(e): Week 2 (PC)

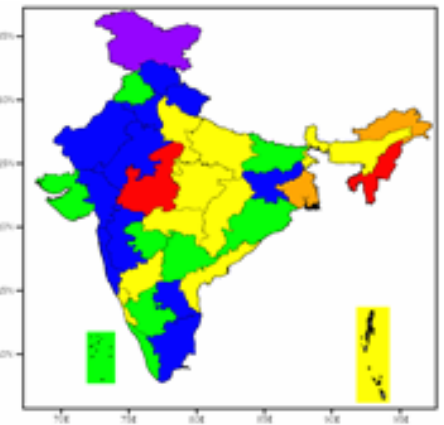

(h); Week 2 (PC)

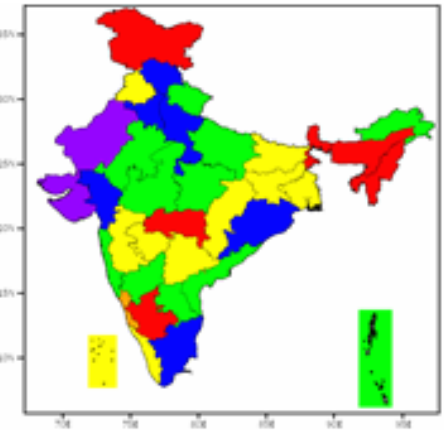

(k); Week 4 (PC)

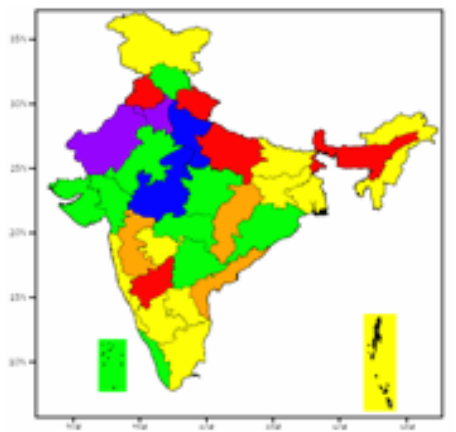

$20 \% \quad 30 \% \quad 40 \% \quad 50 \%$ (c): Week 1 (W)

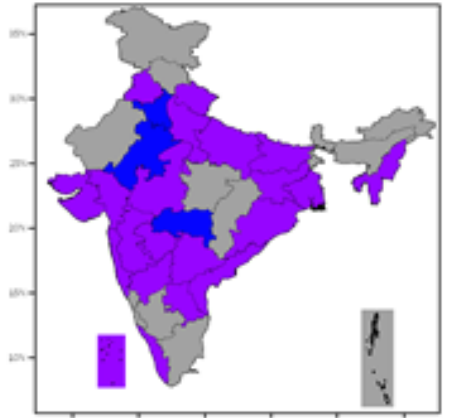

(f): Week 3 (W)

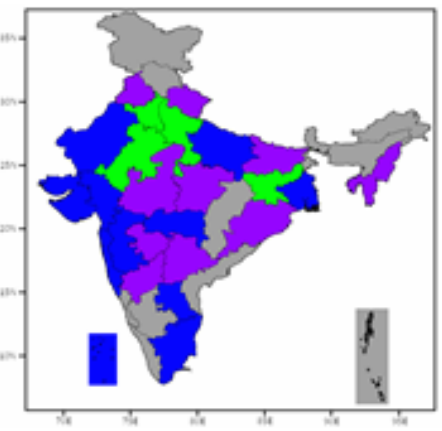

(i); Week 3 (W)

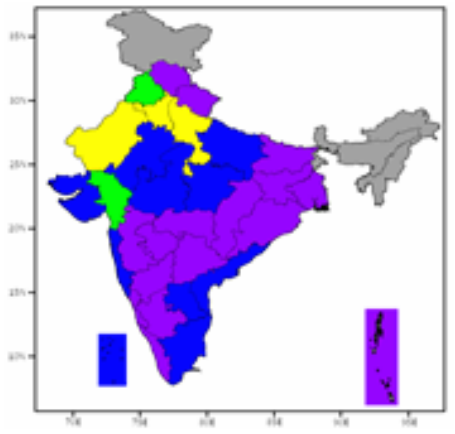

(I); Week 4 (W)

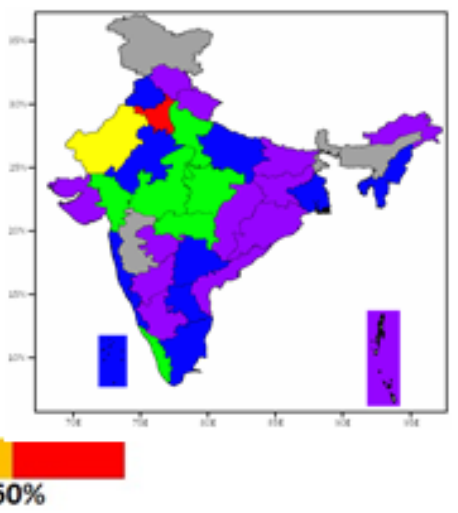

Figure 12

(a) Spatial distribution of week 1 Met-subdivision level forecast skill during 2020 monsoon season as per the contingency Table $1 \mathrm{~b}$ in terms of correct \%, partially correct \% and Wrong \%. (b) to (d) same as 'a' but for week 2, week 3 and week 4 forecast. 


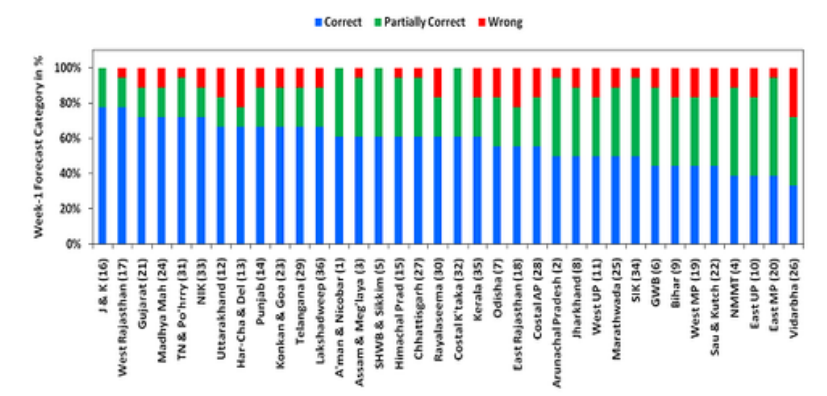

a

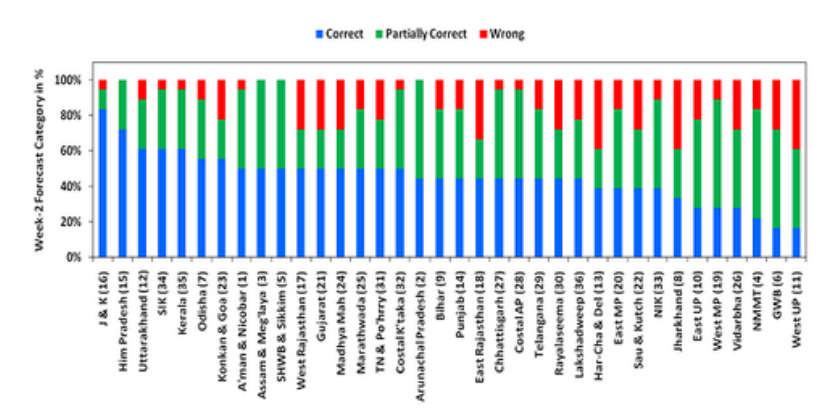

b

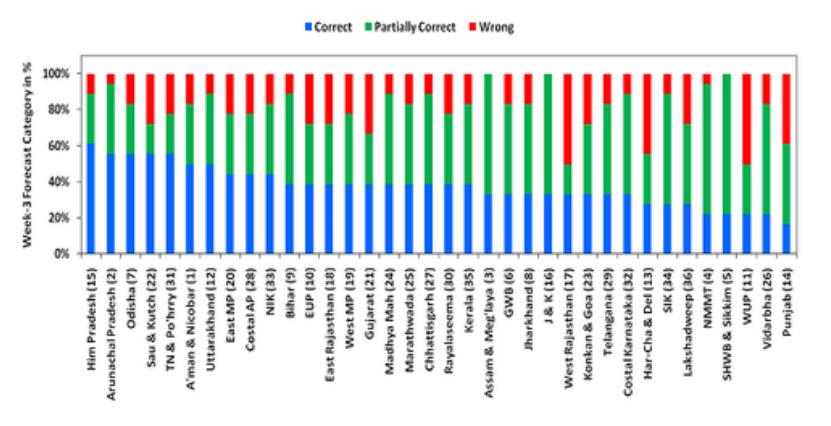

c

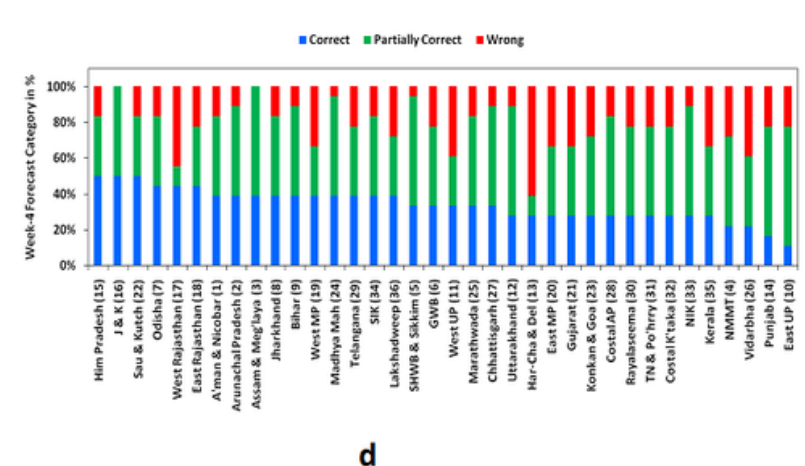

Figure 13

(a) Week 1 forecast skill (b) Week 2 forecast skill (c) Week 3 forecast skill (d) Week 4 forecast skill (a) Week 1 Met-subdivision level forecast skill during 2020 monsoon season as per the contingency Table 1b in terms of correct \%, partially correct $\%$ and Wrong \% with decreasing order of correct $\%$ category. (b) to (d) same as 'a' but for week 2 , week 3 and week 4 forecast. 

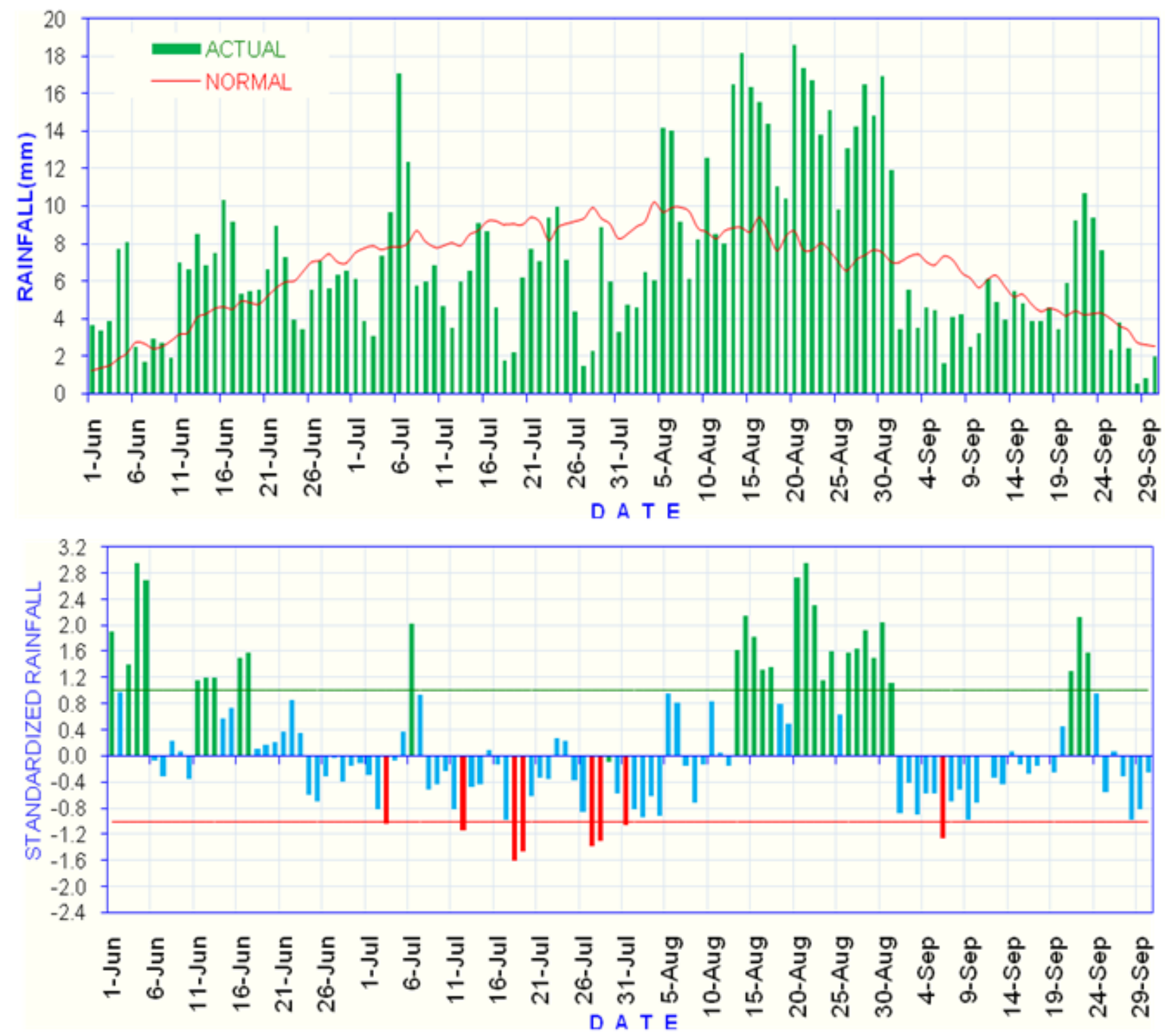

Figure 14

(a) Daily average rainfall $(\mathrm{mm})$ over the core monsoon zone region during monsoon season 2020 from June to September. (b) The corresponding standardized rainfall anomalies over the core monsoon zone region during 2020. 
(a) Observed (24-30 Jul)

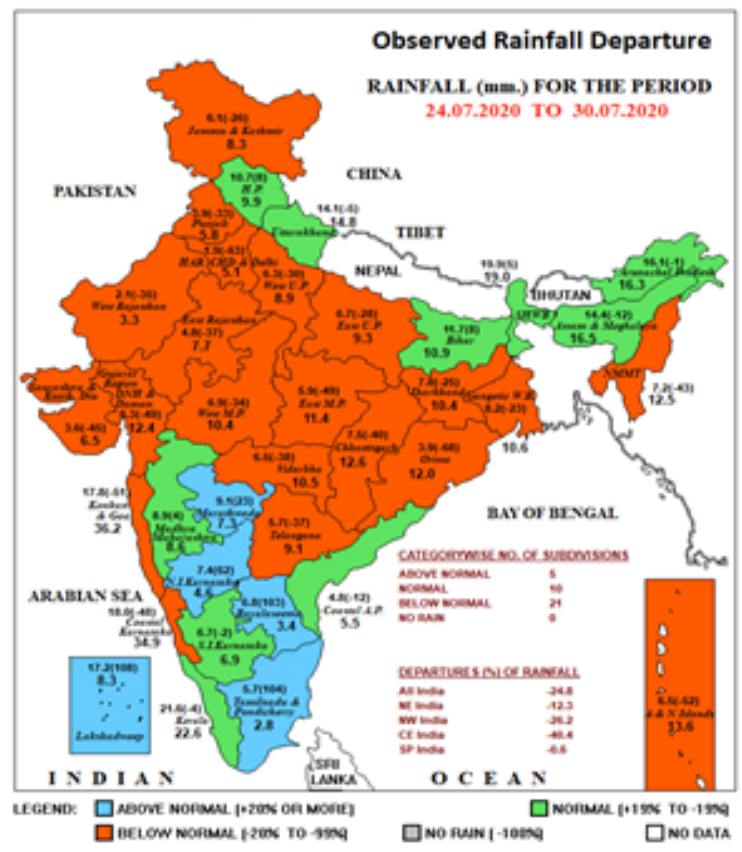

(c) Observed (07-13 Aug)

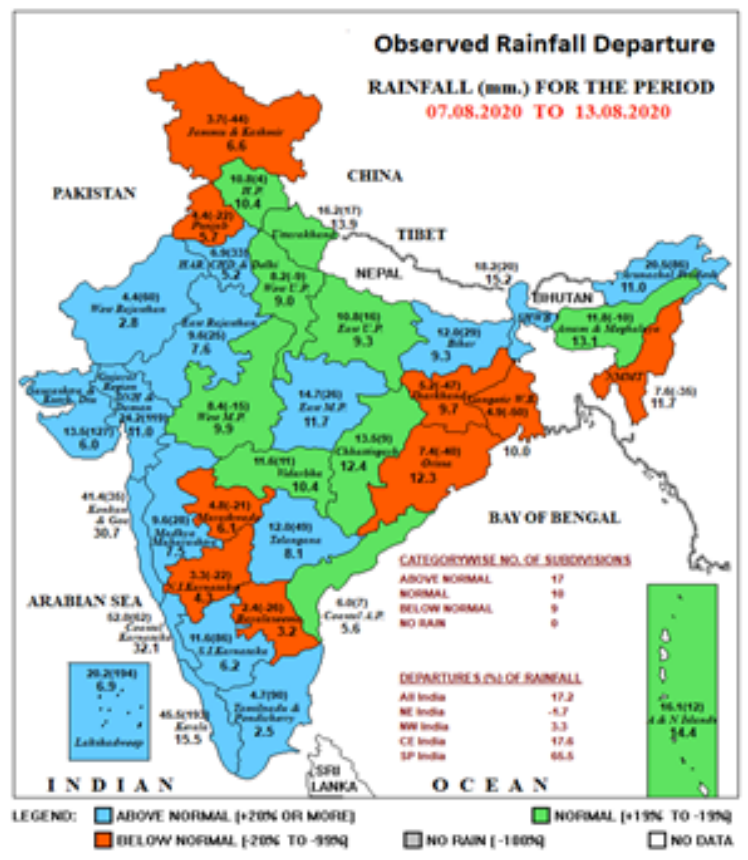

(b) Observed (31 July-06 Aug)

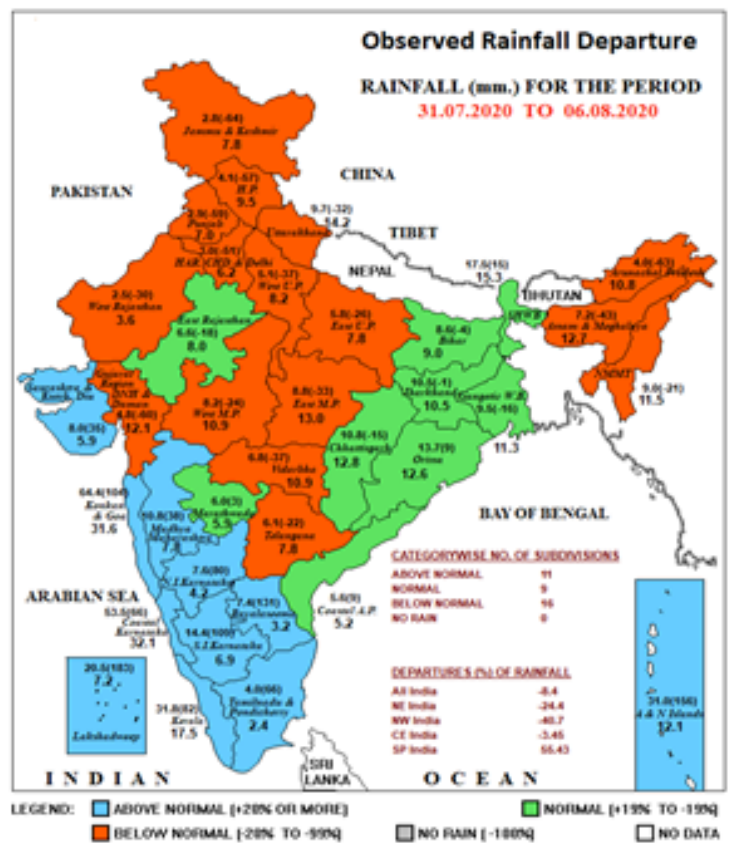

(d) Observed (14-20 Aug)

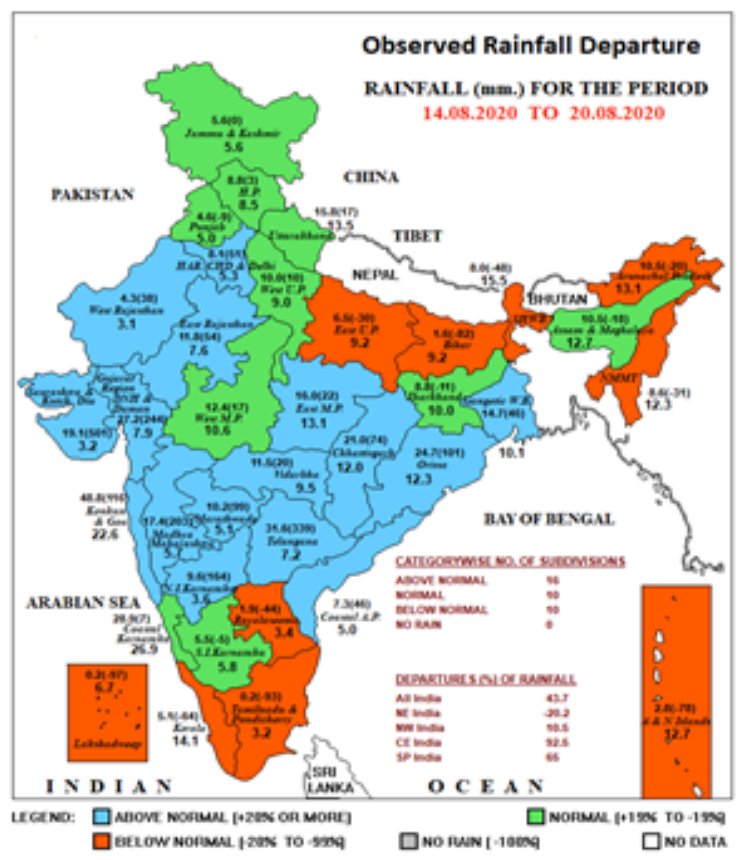

\section{Figure 15}

(a) to (d) Observed weekly rainfall departure at met-subdivision level during the 4 weeks period from 24 July to 20 August 2020. Small figures indicate actual rainfall $(\mathrm{mm})$ in the week and bold figures indicate normal rainfall with percentage departures given in bracket. 
(a) Week 1 forecast (24-30 Jul)

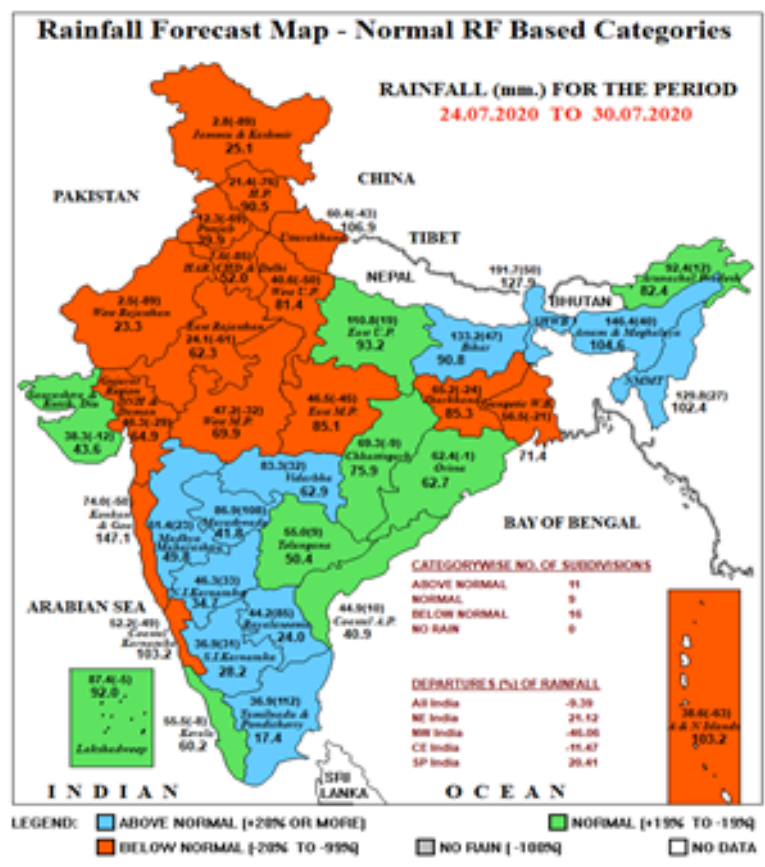

(c) Week 3 forecast (7-13 Aug)

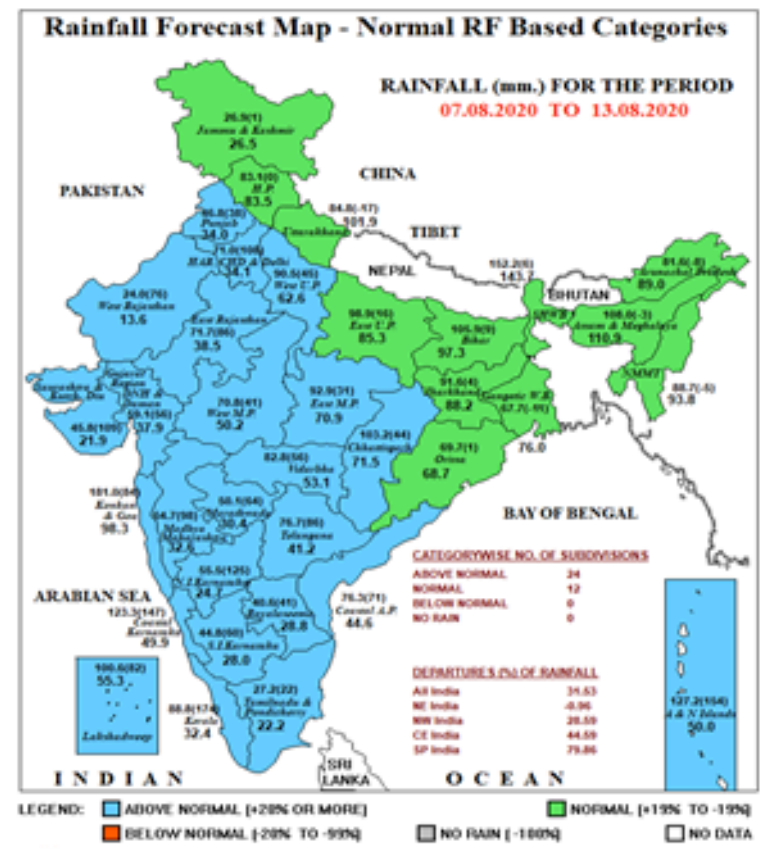

(b) Week 2 forecast (31 July-06 Aug)

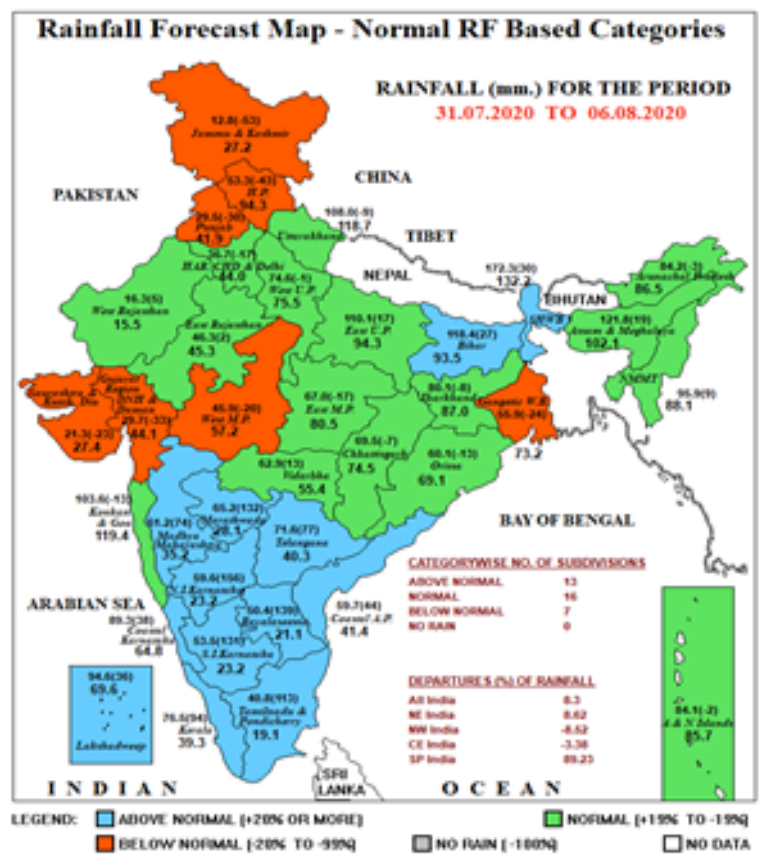

(d) week 4 forecast (14-20 Aug)

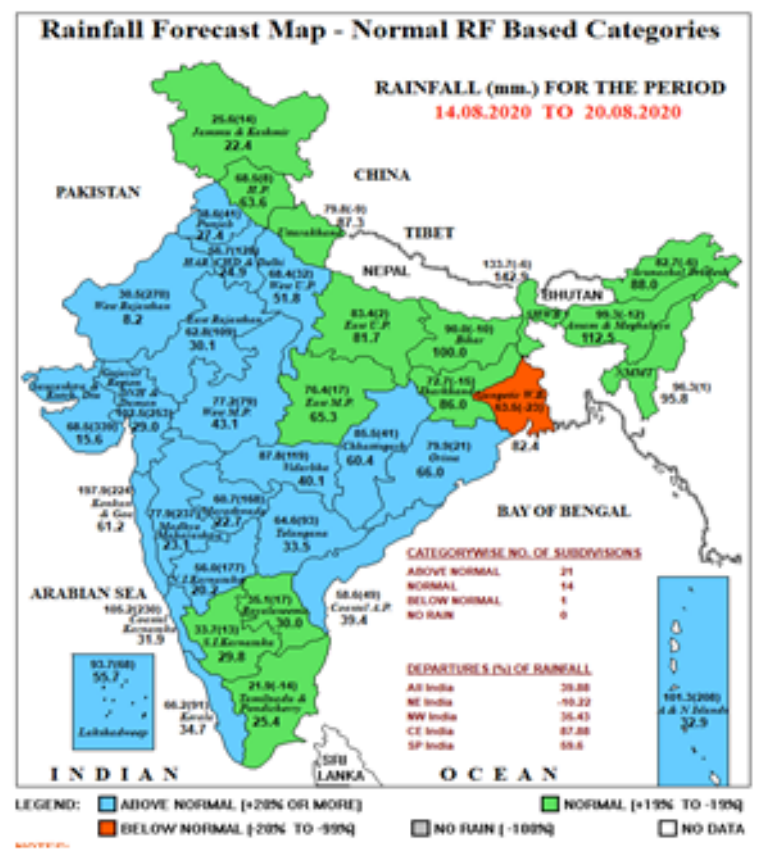

\section{Figure 16}

(a) \& (b) Week 1 and week 2 ERF based on IC of 22 July, 2020 at met-subdivision level valid for 24-30 July and 31 July-06 August, 2020. (c ) \& (d) Same as (a) \& (b) but for week 3 and week 4 forecasts valid for 07-13 August and 14-20 August respectively. 


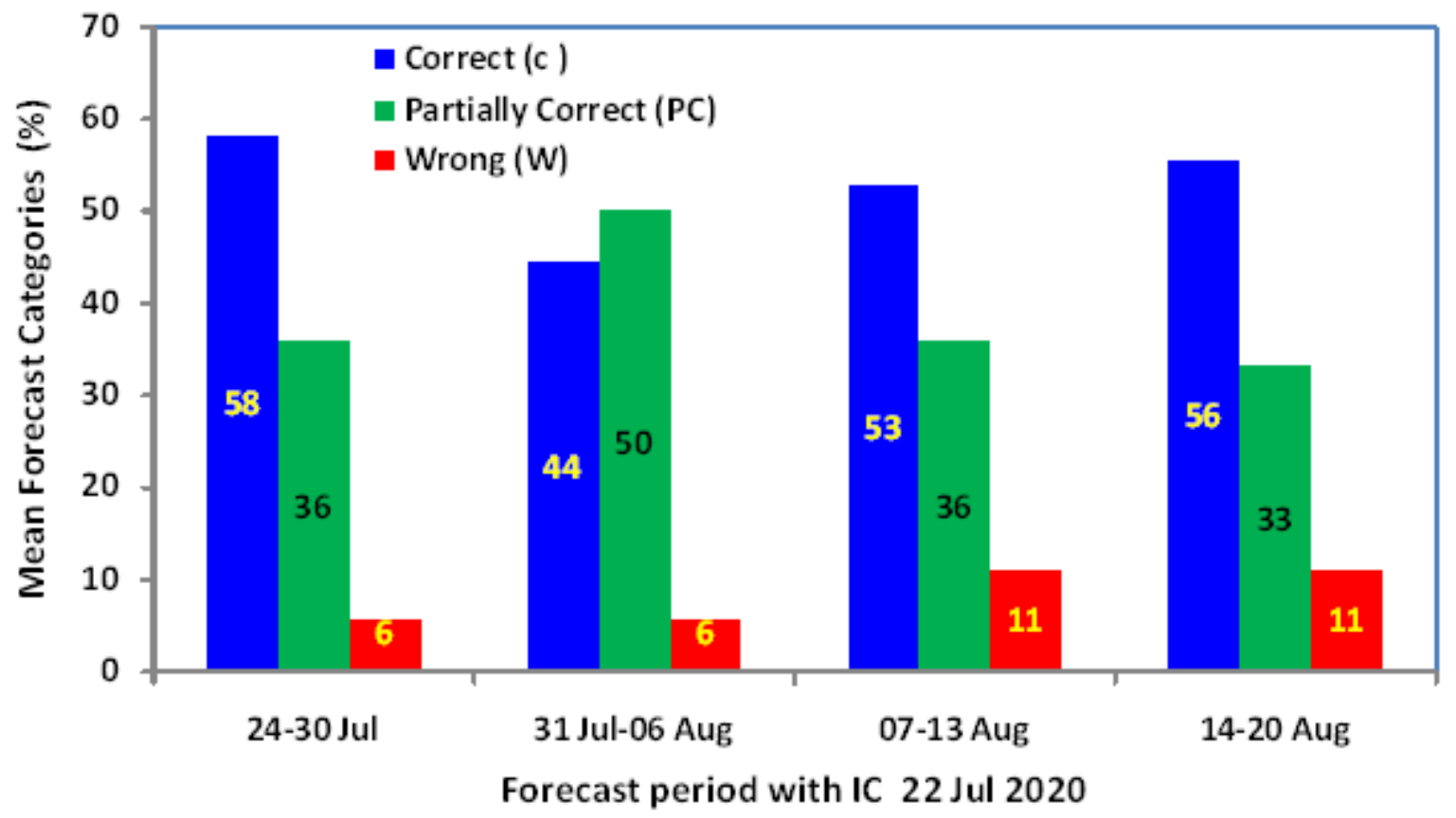

Figure 17

The verification skill score (in \%) of met-subdivision level forecast in terms of correct (C), partially correct (PC) and wrong (W) for 4 weeks based on IC of 22 July, 2020.. 